\title{
Pastoralist societies in flux: A conceptual framework analysis of herding and land use among the Mukugodo Maasai of Kenya
}

\author{
Stephanie Hauck ${ }^{1,2^{*}}$ (D) and Daniel I. Rubenstein ${ }^{1,2}$
}

\begin{abstract}
Pastoral livelihoods are evolving rapidly. The emergence of globalized markets and the integration of globalized production in developing countries have forced many pastoralists, along with the rest of the world's consumers, to shift their economic strategies of production to accommodate these evolving markets. The objective of this paper is to illustrate the relationship between globalization and apparent transformations in pastoralist behaviour in recent years. We specifically focus on the links among climate, land use, and herding in rural northern Kenya. To do this, we use a novel conceptual framework that incorporates both traditional interactions between pastoral ecology and resource generation and modern opportunities by linking pastoral families via their pastoral production and other economic activities to the cash economy, modern diets and nutritional status (health), and public and private assistance and programmes (such as food aid).
\end{abstract}

Keywords: Pastoralism, Globalization, Transitions, Land use, Movement, Kenya, East Africa

\section{Introduction}

Pastoral livelihoods around the world are evolving rapidly. The majority of Africa's pastoral populations have been settled for more than 40 years, and new studies generating old hypotheses about the consequences of settlement for pastoralists are no longer relevant. Today's scientists have a prime opportunity to extend the field of pastoral research to include new themes and assemblages of scientific and indigenous knowledge that more accurately reflect the current lives of pastoralists around the world. By documenting the range and diversity of everyday experiences of pastoralists in today's ecological and economic climates, we can present fresh ideas about how pastoralists manage their livelihoods in the face of new challenges and opportunities provided by markets. These experiences translate into a myriad of embedded social, political, and economic reasons for tapping into the global market, many of which represent new ways of minimizing or dealing with risk in an uncertain ecological and

\footnotetext{
* Correspondence: sjhauck@gmail.com

'Department of Ecology and Evolutionary Biology, Princeton University, 106 A Guyot Hall, Princeton, NJ 08544, USA

${ }^{2}$ Mpala Research Centre, P.O. Box 555, Nanyuki, Kenya
}

economic environment (Catley et al. 2013; Gertel and LeHeron 2011; Zaal 1999).

Market relationships are an integral part of today's pastoral livelihoods. However, these new sets of pastoral actors are vulnerable to variation in social and political forces frequently outside of their control. In short, pastoralists cannot escape the market as their new arena of social and monetary exchange, nor can they transcend their traditional life ways or fully return to them. These factors make it necessary to call for alternative lines of questioning and hypothesis generation about pastoralism and pastoralist's lives, particularly as we explore current livelihood practices and pastoral economics in our highly globalized world.

This paper examines how globalization and engagement with local and regional markets are transforming traditional pastoral behaviour and livelihood outcomes, focusing on the links among rainfall and vegetation, land use, and herding for Mukugodo Maasai pastoralists in Laikipia County, Kenya.

First, we will introduce a conceptual framework as well as some general postulates and theories that help us define the methods, study design, and theories applied to this study. Then, we will review previous works on East 
African pastoralism in order to direct the analysis, presentation, and interpretation of our results. In particular, we will focus on relevant case studies and examples from Kenyan pastoralist groups where possible. After introducing our conceptual framework, we will use field data to systematically evaluate linkages and feedbacks between ecology (rainfall and vegetation), resource generation (pastoral productivity), and household wealth among Mukugodo pastoralists.

\section{New modes of scholarship on pastoralism}

Recent scholarship on pastoralism has benefitted from shifting its focus away from traditional views of pastoral economics to more modern approaches that incorporate the important links between globalization, local markets, migration, economic opportunities, and traditional pastoral livelihoods (Bollig and Lesorogol 2016; Bond 2014; Catley et al. 2013; Galaty 2016; Gertel and LeHeron 2011; Jandreau and Berkes 2016; Kibet et al. 2016; Mwangi 2016; Watson et al. 2016). These new opportunities have subsequently generated new behavioural adaptations and economic strategies that require us to reclassify many of the livelihood tactics and approaches used by modern pastoralists we presented in Table 1. Although not discussed in detail in the text, we summarize a few of these strategies and opportunities as they occur in the Kenyan context in Table 1.

Taking a close look at Table 1, we can see that new economic, social, and educational opportunities and benefits derived from integration into global markets have to be weighed against the risks of dependency, loss of control, and the transfer of benefits to third parties, such as traders in regional and global markets, particularly for the most vulnerable groups (such as marginal pastoralists and labour migrants). Orienting production towards global markets is risky for modern pastoralists primarily because market structures are designed to respond to cash and not the needs of the most vulnerable or 'cashless' members of society (Brinkman et al. 2009; Christian 2010; Darmon and Ferguson 2002). As such, integration into the market forces the poor to incur greater risk than they would under a system of subsistence only production. For example, producing milk for home consumption requires fewer labour inputs than producing steers for slaughter (Dietz et al. 2001) but is similarly subject to external shocks, such as drought (McPeak 2004).

\section{The new normal: Pastoralism in the globalized era}

This paper generates a novel conceptual framework that incorporates more traditional notions of the interaction between pastoral ecology and resource generation to investigate recent transitions in pastoral livelihoods. Our model extends traditional models of pastoralism by linking pastoral families via their pastoral production and other economic activities to the cash economy, modern diets and nutrition, public and private assistance and programmes (such as food aid), and clinics.

In this paper, we offer a number of general theories and propositions in the form of hypotheses about the ways in which Mukugodo pastoralists function under current conditions of globalization.

1. Although usually associated with livestock production, pastoralists engage in a wide range of varied economic

Table 1 Alternative designations of pastoral livelihood strategies and opportunities in the global age of pastoralism

\begin{tabular}{|c|c|c|c|c|c|c|c|c|c|}
\hline $\begin{array}{l}\text { Livelihood } \\
\text { designation }\end{array}$ & Residence & $\begin{array}{l}\text { Household } \\
\text { security }\end{array}$ & Herd size & $\begin{array}{l}\text { Labour and } \\
\text { capital }\end{array}$ & Social welfare & $\begin{array}{l}\text { Use of } \\
\text { cash }\end{array}$ & $\begin{array}{l}\text { Commercial } \\
\text { involvement }\end{array}$ & $\begin{array}{l}\text { Economic } \\
\text { diversification }\end{array}$ & Education \\
\hline $\begin{array}{l}\text { Traditional } \\
\text { pastoralists }\end{array}$ & Mobile & High & Large & $\begin{array}{l}\text { Use family labour } \\
\text { and gain capital } \\
\text { from large herd }\end{array}$ & $\begin{array}{l}\text { Give out large } \\
\text { numbers of } \\
\text { animals }\end{array}$ & Minimal & $\begin{array}{l}\text { Not active, but } \\
\text { have non- } \\
\text { commercial } \\
\text { investments }\end{array}$ & $\begin{array}{l}\text { Cultivation, milk } \\
\text { sales, and } \\
\text { exchange } \\
\text { pastoralism }\end{array}$ & $\begin{array}{l}\text { Little to } \\
\text { none }\end{array}$ \\
\hline $\begin{array}{l}\text { Marginal } \\
\text { pastoralists }\end{array}$ & Sedentary & Low & $\begin{array}{l}\text { Very } \\
\text { small }\end{array}$ & $\begin{array}{l}\text { Lack of capital } \\
\text { and labour }\end{array}$ & $\begin{array}{l}\text { Usually receive } \\
\text { animal gifts } \\
\text { from others }\end{array}$ & Moderate & $\begin{array}{l}\text { Not active; } \\
\text { labourers not } \\
\text { employers }\end{array}$ & $\begin{array}{l}\text { Cultivation, wage } \\
\text { labour, seasonal } \\
\text { jobs, petty trade, } \\
\text { and hired herders }\end{array}$ & $\begin{array}{l}\text { Little to } \\
\text { none }\end{array}$ \\
\hline $\begin{array}{l}\text { Labour } \\
\text { migrants }\end{array}$ & $\begin{array}{l}\text { Split home } \\
\text { base/place of } \\
\text { employment }\end{array}$ & Moderate & Small & $\begin{array}{l}\text { Use family labour } \\
\text { when possible; } \\
\text { access to cash can } \\
\text { generate capital }\end{array}$ & $\begin{array}{l}\text { Usually receive } \\
\text { animal gifts } \\
\text { from others }\end{array}$ & High & $\begin{array}{l}\text { Not active; } \\
\text { use market to } \\
\text { generate } \\
\text { subsistence }\end{array}$ & $\begin{array}{l}\text { Wage labour, cash } \\
\text { livestock trade, and } \\
\text { remittances }\end{array}$ & $\begin{array}{l}\text { Some } \\
\text { primary }\end{array}$ \\
\hline $\begin{array}{l}\text { Pastoral } \\
\text { quitters }\end{array}$ & Sedentary & Moderate & Small & & $\begin{array}{l}\text { Not engaged } \\
\text { in gifting or } \\
\text { receiving } \\
\text { social welfare }\end{array}$ & High & $\begin{array}{l}\text { Active, but only } \\
\text { to trade animals } \\
\text { for cash in market }\end{array}$ & $\begin{array}{l}\text { Wage labour, trade, } \\
\text { small business, or } \\
\text { employment }\end{array}$ & $\begin{array}{l}\text { May obtain } \\
\text { high level of } \\
\text { education }\end{array}$ \\
\hline $\begin{array}{l}\text { Commercial } \\
\text { pastoralists }\end{array}$ & Sedentary & High & Large & & $\begin{array}{l}\text { Not engaged } \\
\text { in gifting or } \\
\text { receiving } \\
\text { social welfare }\end{array}$ & High & $\begin{array}{l}\text { Very active, } \\
\text { produce livestock } \\
\text { for meat trade, } \\
\text { offtake high }\end{array}$ & $\begin{array}{l}\text { Fenceless ranching, } \\
\text { animal breeding, } \\
\text { meat production, } \\
\text { use of hired labour } \\
\text { to cultivate crops }\end{array}$ & $\begin{array}{l}\text { May obtain } \\
\text { high level } \\
\text { of education }\end{array}$ \\
\hline
\end{tabular}


and social activities not exclusive to livestock rearing, traditionally as well as today. Hence, pastoralism can be defined as a social/cultural identity as well as an economic practice of production.

2. Livestock herds and herding activities still act as a major determinant of overall household structure and function, even for families who have diversified into other economic opportunities.

3. The majority of pastoral households are now engaged in some form of contact or interaction with the global economy. Whether this engagement is achieved through purchases and sales at a local market or urban centre is inconsequential.

4. Pastoralists still use a system of seasonal migration or mobility to maintain herd productivity where possible. This requires negotiation with neighbouring communities for access and labour.

5. Social services and other resources provided by private and public partners are essential to the survival and functioning of pastoral communities in their current state of development.

6. Engagement with the global market has intensified existing disparities in wealth, social position, and educational attainment among pastoral households living in similar environments.

In order to contextualize our study within the broader range of research on pastoral livelihoods, we have generated a conceptual framework that ties new activities to traditional ones in order to depict the current socioecological and economic conditions and practices of pastoral livelihoods in Laikipia, Kenya. Our framework thus identifies activities and linkages that illustrate the process of rapid internal social and economic differentiation via access to cash. Under these conditions of rapid differentiation, differences among households in wealth (livestock or otherwise) and social position act as a filter that bins households into quantitatively distinct sets of social, economic, and ecological opportunities and strategies.

\section{Globally integrated pastoralism: A model of the new normal}

Our conceptual framework works off what we call the new normal of pastoralism' (Figure 1).

Our framework makes a few assumptions about the current Kenyan pastoral system. We accept the

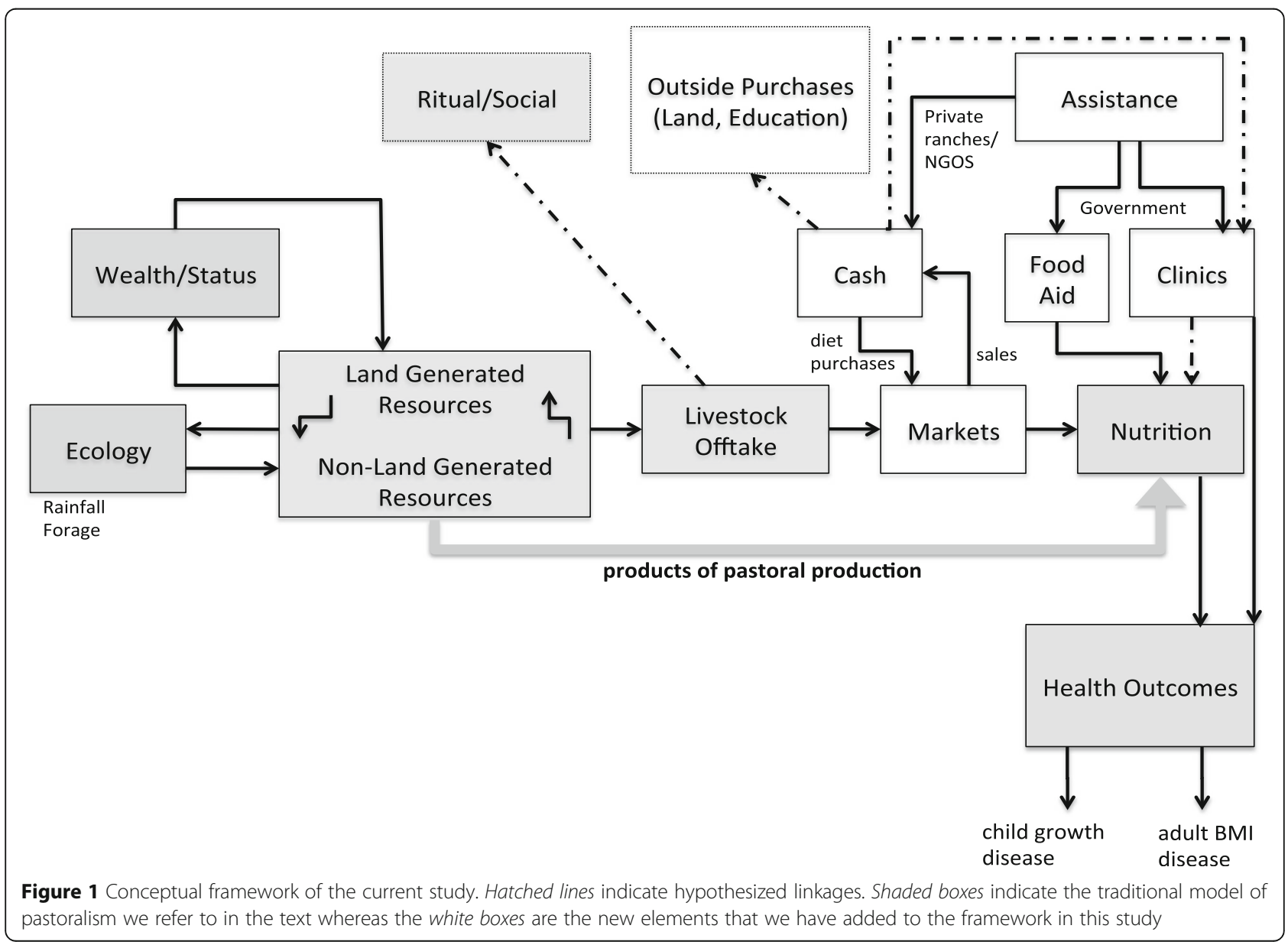


traditional view that pastoralists live in a world that continues to be structured by ecological factors outside of their control, so-called exogenous factors such as rainfall, temperature, and climate, among others. Inside of this uncertain environment, pastoralists engage in various kinds of resource generation, whether via traditional livestock-forage interactions or newly adopted petty trade, wage labour, agriculture, or a combination of these. The outcomes of these new resource-generating activities are then directed towards two primary outcomes: cash generation to meet basic needs and subsistence production to contribute to the diet and well-being of their children and family.

As such, we hypothesize that some pastoral products are used for subsistence and others for sale in a local or regional market. We predict that weekly or bi-monthly regional markets are the most common source of market engagement. Pastoral actors bring their local products to market (milk, skins, whole animals) seeking to sell them for cash rather than exchange via trade. We predict this cash is then used to purchase much needed food items, basic needs, and health care. Sellers in effect should act as currency exchangers for rural producers who have no access to banking, allowing them to convert their products of pastoral production into cash to purchase nonpastoral goods. Since livestock sellers in theory gain cash in the local market and then use it to purchase goods from regional sellers, these pastoral actors effectively take currency out of rotation in their own local community and redistribute it back to urban centres, thereby tethering pastoral actors to agricultural and urban actors to generate capital for basic needs.

Pastoral families have two types of stock options they can sell to acquire cash in regional markets (Dahl and Hjort 1976; Herren 1989). They can sell small stock (goats or sheep) thereby gaining a small amount of cash (the equivalent to taking out cash from the bank to do the weekly shopping) or large stock (cattle and camels) thereby gaining a large packet of wealth to use for health care, education, or other needs that usually require large sums of cash. We recognize that some families also have savings accounts 'off the hoof' they draw on to use for purchases in the market rather than selling stock. Therefore, we consider wealth in this model to be a composite measure of a family's overall assets: labour (access to free familial labour via progeny), livestock (total livestock unit (TLU)), wages (monthly value), savings (in a bank, not on the hoof), and social position (person of status or power). Thus, we hypothesize that access to cash from engagement with diversified practices and regional markets generates socio-economic differentiation among pastoral households under current economic conditions.

We predict that this differential access to cash will influence which households can access services required for family growth and survival, such as health care, education, affordable and safe housing, water, and food, among others. In essence, our model extends traditional frameworks of pastoral livelihoods to include a new set of dynamic pastoral actors who are fully integrated into a cash market. Under the current global economic system, interaction with the cash market facilitates actors to both subsist on and supply local products to regional markets while simultaneously also consuming globally produced products, such as medicines, clothing, and processed foods.

Globalization, with its focus on the free movement of goods, services, technology, and capital, has influenced pastoral lifestyles in a number of ways: exposure to mass media, globalization of food processing, and global shifts in the use of technology and transportation (Popkin 1994; Popkin 2006). Adoption of western goods and global life ways are problematic for pastoralists for two reasons: shifts in access to information and dietary choice/ preference. We hypothesize that globalization and access to regional markets where global products are sold are likely to influence other aspects of pastoralist livelihoods as well. Increased use of cell phones, radios, and TVs means that some, but not all, households have up to the minute access to information, news, and media reports about goods and services from Africa and beyond. For those who have access to information technology, new ideas for marketing, herd management, and migration routes differentiate household livelihood strategies via novel opportunities and constraints presented by regional markets under the process of globalization.

Lastly, our conceptual framework of pastoral livelihoods predicts a high degree of mixing among private and public landowners in recent years. Pastoralists who live in group ranches (communal ranches) also live adjacent to private ranchers and farmers. These households subsequently gain assistance in the form of grants, employment, rations, mobile clinics, and emergency transportation from private neighbouring ranches. In turn, private ranchers use these assistance networks to negotiate with pastoral neighbours for developing wildlife conservancies and eco-tourism and holistic management of grazing patches. We hypothesize that out of necessity, pastoralists and ranchers must engage in shared negotiations in order to find mutually acceptable solutions to the problem of shared access to local resources, particularly traditional grazing patches. In many parts of East Africa, pastoral families must compete with endangered species conservation and eco-tourism (Gadd 2005; Muthiani et al. 2011; Wambuguh 2007) for access to grazing. When forage dries up or droughts arise, families have to either rent grazing land from their neighbours or risk migrating across private/public parcels to distant pastures in western and southern highlands (Herren 1988; Huho et al. 2009; et al. 2011). 


\section{Analytical approaches}

In this paper, we investigate herder level strategies in Mukugodo in order to evaluate how intra-group herding decisions vary in response to a range of environmental conditions, such as drought. From these data, we explore how variation in social and economic status leads to differences in herding decisions among households in response to environmental conditions.

We use the pastoral household as the unit of measure. The household is important because it allows us to test the claim that households employ a wide range of herding strategies with qualitatively different outcomes and that these strategies have been altered via privatization of traditional grazing patches by colonial settlers and integration into national markets, among other things, such as land reform and more frequent droughts. Swedish anthropologist Urs Herren's previous fieldwork with Mukugodo families in the 1980s demonstrated that poor families suffered higher livestock losses during drought, partly because they had trouble mobilizing labour for migration, forcing them to stay in the home area with their flocks when conditions are bad (Herren 1987; 1988; 1989). Herren found that poor households use two principal strategies to acquire capital: remittances and wages from working as migrant labour or opportunistic livestock sales to pay for basic needs. They rarely migrate, struggle to acquire sufficient labour for herding (especially since most children are in school these days), and lose a disproportionate number of livestock during droughts. On the other hand, rich households were more dependent on commercial livestock transactions than wages for capital; tended to lose fewer total animals during drought; had access to external sources of labour, such as hired herders; and migrated with their herds to new areas when conditions were bad.

There is a long tradition of research in pastoral communities on differences in decision-making and socio-economic strategies in the face of environmental modification such as degradation and land use change (Fratkin and Roth 1990; Fratkin et al. 2006; McCabe 1987). In Mukugodo, we apply a decision-making framework to assess household herding practices and land use patterns to determine the degree to which these household responses are influenced by ecological factors such as drought and geographic location (such as closeness to water) and/or social factors, such as wealth.

In Kenya in particular, the establishment of group ranches was a major change in pastoral land tenure (Oxby 1981), but much of the research done on pastoralism in group ranches has focused on Kajiado and Narok Districts, near Masai Mara National Park (Bekure et al. 1981; Boone and Wang 2007; Butt 2011; Grandin 1988b; Homewood 1995; Homewood 2004; Homewood and Lewis 1987; Hughes 2005; Nkedianye et al. 2011;
Omosa 2005). We also sought to quantify the role of non-pastoral sources of income on livelihood strategies, and we achieved this through our innovative dynamic wealth ranking system, which incorporates livestock, wages, labour, social status, and other factors to determine overall household economics. This dynamic wealth ranking system is explained in greater detail in the 'Methods' section of this paper. In Mukugodo, we postulate that social and economic differentiation influences household perception and use of different livelihood strategies. As such, we want to know how recent modifications of traditional strategies have influenced herding decisions, herd composition and structure and mobility patterns, and the ability to recover from drought.

Our reasons for choosing to investigate these patterns of livelihood change in Mukugodo are myriad. First, there was limited previous material on decision-making and livelihood strategies in this particular pastoral system (Aktipis et al. 2011; Cronk 1991 and 2004; Herren 1988 and 1989), making it difficult to contextualize the social, economic, and ecological problems that have arisen in recent years due to a long history of confinement isolation and marginalization. Secondly, there has been rapid market integration in this particular region of Kenya since the 1980s (Gertel and LeHeron 2011; Herren 1989; Huysentruyt et al. 2009; McPeak 2004 and 2005), leading to widespread changes in the character of production and the potential for food production, such as shifting production focus away from dairy cattle to trade in goats with urban meat houses. Thirdly, outmigration of labour to neighbouring private ranches and urban centres has led to social and economic differentiation that influences household outcomes by increasing the divergence of strategies and interests among wealth strata (Kaye-Zweibel 2011). Lastly, no proper evaluation of wealth strata or wealth inequality has been carried out in Mukugodo since Herren used informant wealth ranking to stratify households in 1986.

We used a different strategy from Herren to classify households into different wealth categories (Grandin 1988a, as cited in Herren 1988). Informant wealth ranking is an ethnographic method for sorting households into wealth categories using local terms for wealth, community, and household (Grandin 1988a). We believe that innate bias exists among key informants regarding household wealth, making this method less desirable than methods that use an objective, quantitative approach to assess household wealth without introducing the bias of subjective opinions.

We have a unique opportunity to evaluate the shortterm response of pastoral families to a year-long drought inside of a longer-term study. The data we present here seek to investigate these potentially distinct patterns of recovery via an evaluation of environmental features, 
herding behaviour, herd management, drought responses, and mobility patterns. One of our objectives is to better understand how local ecological factors, such as rainfall, interact with wealth dynamics to affect herding decisions as they occur spatially and temporally.

Heterogeneity in wealth has always been a prominent feature of herding cultures. According to Cronk (2004, p. 97), Mukugodo pastoralists were already at the bottom of 'a regional hierarchy of wealth...with the disparity being easy to document since the Mukugodo were last in their region to acquire livestock'. For pastoralists, wealth is usually counted in head of stock, with some herders amassing vast numbers of livestock, while others eke by with a few sheep and goats. It is often the wealthiest herders (e.g. those with the largest, most productive herds) who can marry the most wives and bear the most children, creating a disparity between rich and poor in not only wealth but also production (access to labour) and reproductive success (Borgerhoff Mulder 1992; Herren 1989; Cronk 2004; Fratkin and Roth 2005). However, it is not just wealth per se that leads to greater variability in success among pastoralists. Wealth, in modern times, translates into access to cash and the products of globalization and, most importantly, an increasingly diversified diet.

Weaving wealth differences into this analysis allows us to also evaluate existing social welfare systems, such as osutua and paran, and where and when they fail (Aktipis et al. 2011; Godoy et al. 2007; Smith 2011). Osutua literally means 'umbilical cord' in Maa, making it a term that describes a 'tied' relationship between two individuals (Cronk 2007). Osutua typically refers to a stock friendship or bond between two individuals that is permanent and can be passed onto their children. Bond partners reciprocate requests indefinitely, usually in the form of livestock, although in Mukugodo, virtually any good or service can serve as an osutua gift (Cronk 2007, p. 353), even cash. Paran, on the other hand, are gifts given to poorer members of the community, usually as a result of intense begging on the part of the receiver, or long-term loans which the giver are unlikely to be repaid (Herren 1989). Gifts given under paran are not reciprocal; in fact, givers often complain that compliance with paran was a social necessity but also a 'veritable rip-off' (Chief of Ilmotiok, Tiamamut, and Mpala, personal communication, 2011).

Lastly, this study allows us to evaluate the dynamics of variation in new forms of herd management, particularly modified mobility patterns and shifts in herd structures. These changes alter in turn how families manage mobility in this mixed-use system, which is already constrained by private and public land patches abutting communally managed lands (Gadd 2005; Huho et al. 2011; Wambuguh 2007; see also Figure 11 in this paper).
Mukugodo are in a unique situation among Kenyan pastoralists, in that they live in a region surrounded by large-scale private cattle ranches that also engage in wildlife conservation and tourism, forcing them to compete and/or engage in risky negotiations with more powerful individuals for access to land. In this paper, we evaluate how differential access to local resource distribution (grazing patches) affects production via herding and whether differences in wealth statistically interact with other main effects to shape household decisions and outcomes.

\section{Research objectives}

In this paper, we will characterize (i) the environmental conditions across both space and time of Ilmotiok and Tiamamut group ranches in Mukugodo Division, Laikipia, Kenya; (ii) mobility and local/regional range use patterns by group ranch and wealth class; and (iii) the influence of wealth differences on herding and production strategies that families use to cope with environmental variation or stress.

We do this via the following questions and hypotheses:

1. What environmental factors structure ecological dynamics in our local system? Is livestock productivity tied directly to local rainfall patterns?

We hypothesize that local rainfall patterns will affect livestock productivity via local variation in vegetation quality and accessibility. From this, we predict that increases in rainfall will lead to improved vegetation quality, which will act to increase livestock productivity via higher birth and lactation rates.

2. What migration strategies (seasonal or otherwise) are herders using in Mukugodo to manage local environmental conditions? Does wealth rank act as a social filter that differentiates households by these various strategies (i.e. the ability to negotiate the relationships necessary to move your animals to restricted areas or through restricted areas?)?

We hypothesize that herders should migrate to distant grazing patches when local forage and water conditions decline, such as during droughts or dry seasons. Differences in herding strategy will be separated by wealth via differential access or use of grazing patches on and off group ranches.

3. What are the consequences of environmental variation and herding differences stratified by wealth for livestock productivity (in terms of milk) and household livelihoods? 
We hypothesize that differences in herding strategy and herd management, such as herd size, composition, and structure, will influence household production potential of milk. We predict that herders with access to resources essential for herd growth (such as high quality grazing patches whether local or distant or alternative sources of protein to minimize lactation effort in their herds) will have higher productivity (milk yields) than households without access to adequate resources for herd growth. This will be particularly important during dry seasons or droughts when forage and water resources become scarce in the local grazing area. Lastly, we predict that some herders will be able to rebuild their herds after dry seasons or droughts via herd building strategies, such as purchases or gifts (social redistribution).

\section{Study area}

This study was conducted in two Kenyan Group Ranches: Ilmotiok and Tiamamut, in western Mukugodo Division, Laikipia County, Kenya. The study was designed as a mixed longitudinal cohort study (Goldstein 1968) of socio-economic subsistence practices, diet, and health. Research was conducted with permission from the Kenyan Government (Permit Number: NOHEST13001-29C80 VOLII) and local officials. Ethical approval was granted under Institutional Review Board for the Ethical Treatment of Human Subjects at Princeton University (Protocol \# 4051).

Mukugodo Division covers roughly $1,100 \mathrm{~km}^{2}$ of Laikipia County, representing the north-eastern edge of the Laikipia Plateau (Herren 1988; Herren 1989) (Table 2). On the edges of the plateau, elevation drops from 1,800 to

Table 2 Demographic characteristics of human and livestock populations in Ilmotiok and Tiamamut group ranches, Laikipia, Kenya

\begin{tabular}{lll}
\hline Census data & $\begin{array}{l}\text { Imotiok group } \\
\text { ranch }\end{array}$ & $\begin{array}{l}\text { Tiamamut group } \\
\text { ranch }\end{array}$ \\
\hline Size (hectares) & 3,651 & 5,240 \\
Number of households & 110 & 242 \\
People & 998 & 1,552 \\
Cattle & 207 & 643 \\
Small stock (goats/sheep) & 3,197 & 6,560 \\
Camels & 15 & 113 \\
Chickens & 651 & 716 \\
Hectares of land per person & 3.65 & 3.37 \\
Hectares of land per TLU & 5.13 & 3.03 \\
LLU per person & 0.78 & 1.23 \\
TLU per person & 1.14 & 1.12 \\
\hline
\end{tabular}

This human and livestock population data was collected during a group ranch-wide census campaign in 2010

LLU lactating livestock unit, TLU total livestock unit
2,200 $\mathrm{m}$ to 1,500 to $1,600 \mathrm{~m}$ in Ilmotiok and Tiamamut group ranches (Figure 2). Central Mukugodo is rugged hilly terrain with acacia savanna vegetation. In the west, where the Ilmotiok and Tiamamut group ranches are located, the terrain changes to undulating hills interspersed with acacia savanna and open grasslands (Muthiani et al. 2011) that abut the Ewaso Nyiro River, which is the administrative boundary of the Division.

Annual rainfall in Mukugodo Division is highly unpredictable and declines appreciably from east to west $(700 \mathrm{~m}$ in the east and $400 \mathrm{~m}$ in the west; Herren 1989). The long rainy season usually occurs between the months of March and May. The short rains arrive (if they arrive at all) during late October/early November and usually last until December. During the months of June and July, there is occasionally a third rainy season, with localized rainfall generated from non-monsoonal rains off the shores of Lake Victoria (for more detail, see Taylor et al. 2005). In drought years, the long rains are very short or do not come at all, and the short rains are absent. In wet years, the long rains are on time, last for three months, and are followed by a shorter dry season with occasional showers, with timely short rains. Forage levels (annual and perennial grasses) vary with the localized rainfall pattern and can literally grow overnight in response to a good rain.

There are two perennial rivers in the system, the Ewaso Nyiro and Ngare Ndare, which is unique in semiarid pastoral settings (Borgerhoff Mulder 1992; Butt 2010; Homewood 1995 and 2004; McCabe et al. 2010; Scoones 1995; Sellen 1999, 2000, 2003; Thornton et al. 2007; Yanda and William 2010). These rivers provide a reliable source of water for livestock, wildlife, and human populations on the western boundary of the Division without necessitating borehole development.

Western Mukugodo is isolated from Dol Dol, the administrative centre, in the north and Nanyuki, the district centre, in the south. In the south, the Division is bounded in by large-scale private ranches, most of which maintain closed electric fences along their perimeter and patrols on both public and private access roads (Herren 1989; Huho et al. 2011; Muthiani et al. 2011; Ngugi and Conant 2008). On the northern side of the Division, there is a livestock holding ground, which is now settled by Samburu pastoralists, and a second livestock holding ground in the southwest, which is now privately owned (Dan Rubenstein, personal communication, 2012). The Ewaso Nyiro River also creates an impassable boundary during wet periods (or when the flower farms downstream unload their dirty water onto pastoralists upstream), making the Ilmotiok group ranch in particular an island for part of the year.

Mukugodo Division, which is made up of resettled Mukugodo Maasai pastoralists, was created in 1936 (Herren 1987 and 1988; Spencer 1959) as a Native 


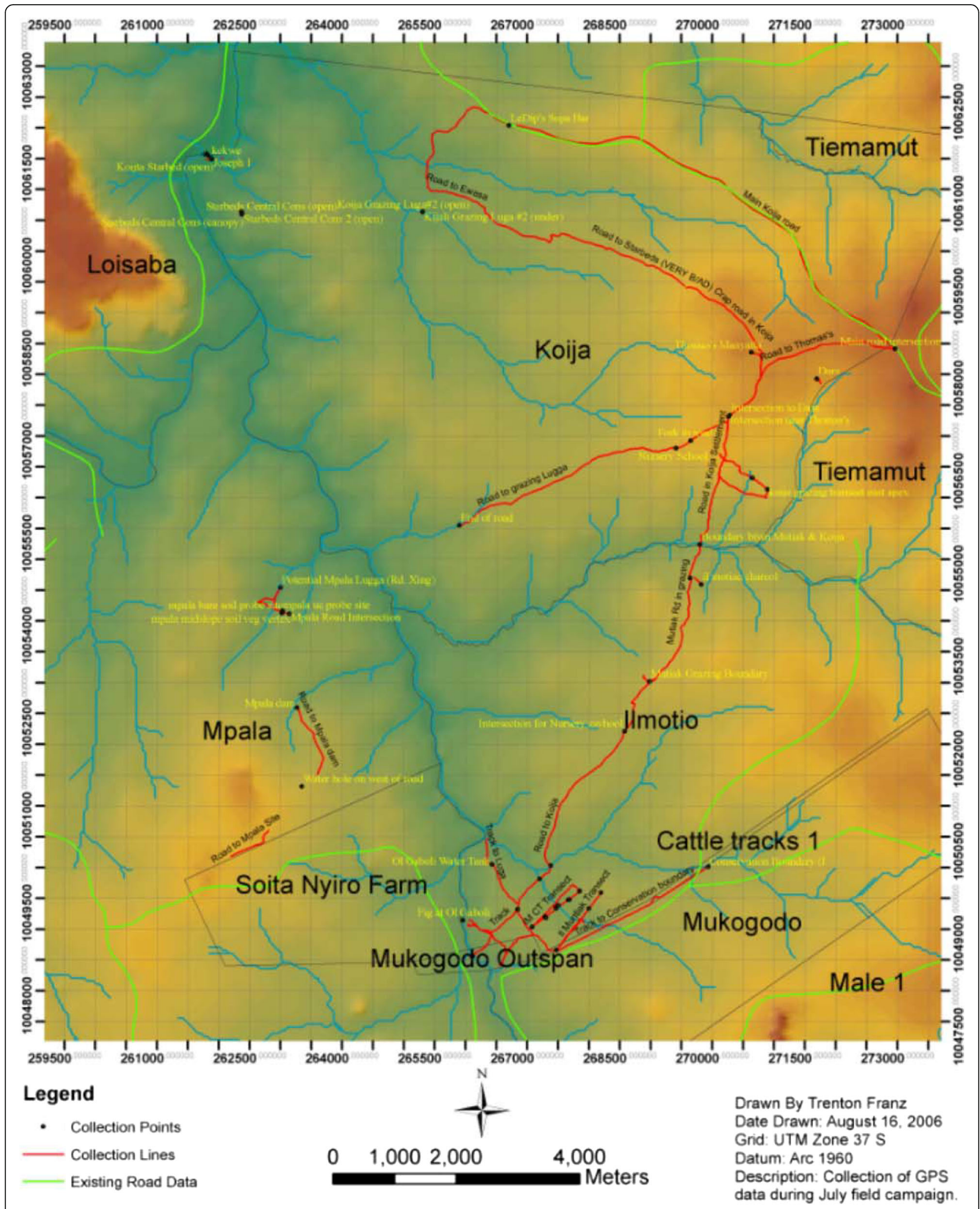

Figure 2 Detailed map of the study area. Research was carried out in the IImotiok and Tiamamut group ranches. Trenton Franz generated this map in collaboration with the Ewaso Water Project in 2006 
Reserve for 'Dorobo' pastoralists left behind on the Laikipia Plateau after the pastoral resettlements of 1914 (Spencer 1959). These individuals represent five distinct ethnic groups (Leuaso, Digirri, Mumonyot, Ilng'wesi, and Mukugodo; Cronk 2004) who differ in historical background, social organization, and ritual behaviour, although they all speak Maa as a common language (Herren 1987). Only becoming livestock herders in earnest in the 1950s, they did so under duress; the majority of their land was lost to war and colonial settlement in the 1920s (for the complete history of the Laikipia Wars, see Spear and Waller (1993)).

The catastrophic droughts of the 1980s devastated the Mukugodo Maasai living in this Division (Herren 1987). Since then, the region has been characterized by high levels of outmigration; ecological problems, such as degradation and the influx of invasive species (King 2008); and the need for long-term famine relief (Caritas Kenya, personal communication, 2010). However, these changes have not led to reductions in population size in the region: between 1987 and 2010, the human population grew from 11.7 to 36.69 persons $/ \mathrm{km}^{2}$ (Herren 1987).

Pastoral families in this region currently raise four species of livestock: cattle, goats, sheep, and camels. They separate their herds into feeding groups, with cattle and camels herded in separate groups, and small stock herded together. When total herd numbers are very low (usually less than 15 individuals), these families will graze goats and cattle together, although this is not the preferred arrangement. In this region, animals are raised for the production of milk not meat. As such, herd owners do not typically sell female animals under any circumstance. Male animals, however, are used as shortterm breeders, castrated and then sold or traded, and/or sold as juveniles for quick cash. Maasai herders historically traded with agriculturalists for grains and other foodstuffs during seasons when milk was less abundant (Spear and Waller 1993). In more recent years, semipermanent settlement in trading centres and towns has turned seasonal dependence into complete reliance on neighbouring agricultural groups and humanitarian aid organizations (such as USAID and WFP) for food.

Households are usually polygamous, consisting of a man, his wives, and children, although in recent years, monogamy is becoming more common. Labour is divided among the members of a household along age and gender lines (Herren 1988). Households may choose to cooperate with their neighbours in a 'meta-household' structure. These meta-households normally consist of two or more families that share some degree of genetic relatedness, although this is not a necessary constraint. Meta-households that have chosen to cooperate will typically make 'group' decisions about the movement and management of their livestock herds. Decisions about herd management are centred on obtaining regular access to water and suitable vegetation for grazing.

\section{Methods}

Field research on the ecology of pastoral herding and production was conducted in Ilmotiok and Tiamamut group ranches, Mukugodo Division, Laikipia County, Kenya, between June 2008 and July 2011. Thirty households, with a total of 400 subjects, were enrolled from 2008 to 2009 into a mixed longitudinal cohort study of pastoral populations in rural Northern Kenya. An initial cohort of 16 households was enrolled and visited monthly beginning in June 2008, with a second cohort of 14 households enrolled in July 2009 . We conducted in-house field research with each cohort a minimum of five times over the course of a three-year period, for a total of 15 months of contact time. Furthermore, two locally trained research assistants actively surveyed both of our enrolled cohorts once a month from September 2008 to July 2011.

\section{Historical rainfall and vegetation dynamics in northern Laikipia}

Rainfall and Normalized Difference Vegetation Index (NDVI) values recorded daily via the Global Livestock Early Warning System (GLEWS) database were uploaded for analysis. The database, which was developed by Zola Ryan in collaboration with Mpala Research Centre (MRC) in 2004, monitors climate data from 30 monitoring sites throughout Laikipia County (Ryan 2004). This database uses a coarse grid size of $8 \times 8 \mathrm{~km}$ of land to calculate rainfall and NDVI values for each group ranch-monitoring site. Historical rainfall data (beginning in 1960) was derived from local rainfall recorded provided by MRC and the World Meteorological Organization. Current rainfall and NDVI data are downloaded every 10 days from NOAA RFE and NASA NDVI SAT, respectively.

Here we use the normalized vegetation difference index (NDVI) as a proxy for the green up of forage resources. NDVI is an index that parameterizes the contrast between PAR absorption and NIR reflectance as a gauge of plant productivity (Verbyla 1995). NDVI is calculated from the visible and near-infrared light reflected by vegetation.

The NDVI equation is:

$$
\mathrm{NDVI}=(\mathrm{NIR}-\mathrm{RED}) /(\mathrm{NIR}+\mathrm{RED}),
$$

where RED and NIR are measures of reflectance in the red and near-infrared bands of a sensor system, respectively.

Healthy vegetation absorbs most of the visible light that hits it and reflects a large portion of the near- 
infrared light, giving these plants higher NDVI scores than unhealthy or sparse vegetation, which reflects more visible light and less near-infrared light, giving these types of plants low NDVI scores. The scale ranges from -1 to 1 , where values of less than 0.1 indicate bodies of water or bare patches of ground and values above 0.35 indicate green, dense canopy cover of leaves and other source vegetation. ${ }^{1}$ NASA only started collecting satellite NDVI data in our region in 1981; therefore, all NDVI-rainfall analysis conducted here utilizes this restricted subset of data (1981 to 2012).

We used rainfall and NDVI data from GLEWS for the Ilmotiok (KOI-1) and Tiamamut (TIA-1) group ranches to determine the degree of correlation between rainfall at time $t=0$ (days) and time $t=31$ (days) where NDVI value $=$ time $t=0$ (days) in these two communities. For ease of discussion, we refer to this as a 'one'-month lag; however, to be precise, our analysis operates under 31 days as a month (21-day lag in rainfall +10 days of observed rainfall) rather than 30 days.

Symmetric nearest neighbour locally weighted regression (LOWESS; (Cleveland 1979)) was used to determine significant relationships between rainfall and NDVI and to establish patterns of correlation between rainfall and NDVI. LOWESS is a polynomial smoothing technique that fits weighted least squares linear regression lines to localized subsets of data to describe deterministic variation in the data point by point. The power of this technique is that it takes into account neighbouring points of each point in determining the fit and repeats the entire procedure for each data point until it achieves the best fit.

\section{Short-term trends in rainfall and NDVl: Effects of drought on semi-arid systems}

Once long-term trends in rainfall and NDVI were established, a secondary analysis on a subset of the rainfall and NDVI data was conducted. We extracted these data from the GLEWS dataset mentioned in the previous section. Analysis was restricted to the years 2007 to 2012, which correspond to approximately \pm one years immediately preceding and following the current study (2008 to 2011). Again, LOWESS (Cleveland 1979) was used to determine significant relationships between rainfall and NDVI and to establish patterns of correlation between rainfall and NDVI.

\section{Products of pastoral production survey}

To measure the extent to which pastoral products are available for consumption or sale within this population, we developed a survey technique called Herd Distribution Mapping. This technique quantitatively maps changes in herd composition and distribution for study households within each of the group ranches. We use a combination interview/direct observation technique, with a quantitative outcome. Each participating family was visited once a month where possible (either at the homestead where herds were directly observed and counted or at their dry season camp) and interviewed about the age, sex, and species composition of their complete herd, both those located at the permanent homestead and those out with affines or at dry season grazing zones.

We use these data, which are disaggregated by livestock species, sex, and age class, to calculate a family's dynamic total livestock units (TLU, ILCA $1981^{2}$ ) and lactating livestock units (LLU, ILCA 1981) for comparison with other families in the population. To calculate TLU, multi-species herds are divided into their component parts - cattle, sheep, and goats - and ranked according to their value in the herd. Cattle are given a value of $0.71 /$ head and sheep and goats (shoats) a value of 0.17/head. Camels do not have an ILCA (1981) value. Therefore, we estimate their value to be twice that of a single cow (1.4/head). It is important to note however that camels do not figure prominently in the herds of our families and thus do not make up a significant portion of our calculations (less than 5\%). Our observations of typical family herds in Laikipia indicate they can vary from $<1$ to $>300$, depending on the population. TLU, as a standardized measure, is usually a good indication of a family's access to cash and whether that cash is accessible in small (shoats) or large (cattle, camels) packets of wealth. Similarly, LLU divides multi-species herds into their component parts - cattle, sheep, and goats - and ranks them according to their dairy value. Camels are given a value of $1.4 / \mathrm{head}$, cattle are $0.75 / \mathrm{head}$, and shoats $0.15 /$ head. The number of LLU in a herd varies from month to month and is a good indicator of a family's ability to maintain a productive milking herd. Since most pastoral families do not sell lactating animals under any circumstance, LLU is a good indicator of a family's subsistence value/wealth but not cash wealth.

Data were also recorded monthly on the number and location of herd movements to locales outside of the home range for grazing, number of deaths, number of births, number of pregnant/lactating animals, number sold/bought and their value in the market, ${ }^{3}$ transactions such as gifts and transfers, and animal slaughters. These data were used to determine household wealth (as measured in livestock units), access to small (shoats) and large (cattle and camels) packets of cash income, and production value of the herd (number of new individuals added to herd, number of lactating animals). This information was used to determine herd structure, composition, and mobility patterns.

We use these data on migration of livestock herds by households to determine if herders make migration 
decisions based on ecological factors, specifically rainfall and forage availability. Here we use linear regression to determine if the mean difference in rainfall between migration patches (Kirimun, Sukuton-Naibor, Rumuruti, Segera-Endana, and Mpala) and the home patch is a good predictor of where pastoral families should migrate with their livestock during dry seasons or droughts depending on which community they reside in. All of these grazing parcels are present on a map of Laikipia County included in this paper (see Figure 11). To do this, we used the GLEWS database of rainfall values for Laikipia County to download data for each of the five migration patches listed above and calculate the mean difference in rainfall between the migration patch and the home patch. These differences were tested for significance using a simple regression model at $95 \%$ confidence and then plotted onto a graph. Migration patches were considered significantly different if the mean difference in rainfall was statistically significant and the confidence interval around the mean did not include zero. Significance is noted in the plots generated for this analysis.

Lastly, we measured monthly milk availability by family, which was measured as the amount of milk produced by each species in the herd for family use. To do this, we measured the amount milked in each household (morning and evening) by species. We then disaggregated this data for each family by number of animals milked by species for analysis. In this analysis, we also controlled for family size and lactating herd size when fitting regression models to our data by including these variables in the analysis. Family size is important since larger families would consume less milk per capita than smaller families, so we must control for family size in order to test for actual differences in consumption rates. Secondly, lactating herd size is important because families that have larger lactating herds will theoretically be able to produce and consume more milk than families with smaller lactating herd sizes. Hence, we control for lactating herd size and family size to control for variation in our analysis that may cloud our results.

\section{Wealth classification methods}

In order to determine the socio-economic status of individual families within the study area and the influence that status has on resource acquisition, we generated a numerical ranking system for wealth in this population, which is a linear combination of livestock (TLU/LLU), wages (cash/month), children (labour availability), and status (social mobility and influence). In contrast to past approaches that use a single wealth value to calculate differences among families or an informant ranking approach, we used a novel approach that is dynamic and objective, as stated in the introduction to this paper. It is important to note that we do not use a single wealth value for each household for all years of the study. Knowing that wealth and status can shift dramatically from one year to the next, we instituted a 'dynamic wealth rank variable system' that calculates temporal changes in wealth rank from year to year to determine each household's rank. These yearly values are then used to analyse relationships between wealth and herding strategies in our population.

Families were ranked according to an ordinal scale for status based on observational and numerical data from WHO Equity Assessments ${ }^{4}$ completed with each family member in a given household during the first two years of fieldwork (2008 to 2009). These status ranks are based on objective measures of social mobility, access to external resources, and leadership/government involvement: Status $(0=$ no status; $1=$ association with person of status (POS - either client or relative); $2=$ community leader; $3=$ association with private ranch or other private institution (either employee, relative, or affine of management); $4=2+3$ ).

Principal component analysis was used to calculate the eigenvectors associated with each wealth variable in the expression. Total livestock units and wages in cash weighted heavily in eigenvector 1 , providing approximately $54 \%$ of the variation observed. Labour availability, as represented by the number of children, explained approximately $27 \%$ of the variation. Lastly, status weighted heavily on axis 2 and explained approximately 19\% of the total variation. These eigenvectors, as described above, were then used as constants to weight each variable according to its importance in the model. We labelled these weighting factors as $A 1, A 2$, and $A 3$ in our mathematical expression of wealth. Therefore, wealth rank is determined by the following linear expression:

$$
\begin{aligned}
& \text { ((Livestock wealth }(\text { TLUby species } * \text { cash value in } \mathrm{KsH}) \\
& +(\text { wages in cash }(\text { monthly value in Ksh }) * \mathrm{~A} 1)) \\
& +(\text { of children } * \mathrm{~A} 2)+(\text { status value } * \mathrm{~A} 3))
\end{aligned}
$$

This expression generates a numerical value roughly equivalent to the cash value that a family has access to in a given month (TLU cash - LLU cash + wages) but also the relative cash value of a given household's labour pool (children) to their overall wealth rank in the population. This information can then be used to calculate the income distribution, in local currency, of our sample families.

To further investigate the role of wealth in these communities, we plotted a simple Lorenz curve of income inequality by year to visually inspect income disparities. We then calculated two indices of inequality, the Gini coefficient $^{5}$ (which is based on the Lorenz curve) and Theil's $T$ (which is similar to the Shannon index), to 
provide a numerical estimate of the degree of income inequality we see in the Lorenz curves ${ }^{6}$. The Gini coefficient is determined by the following expression (Deaton 1997, p. 139):

$$
G=\frac{N+1}{N-1}-\frac{2}{N(N-1) u}\left(\sum_{i=1}^{n} P_{i} X_{i}\right),
$$

where $u$ is mean income of the population and $P_{i}$ is the income rank $P$ of person $i$, with income $X$, such that the richest person receives a rank of 1 and the poorest a rank of $N$.

The basic index for Theil's $T$ is represented by the following expression:

$$
T_{T}=T_{\alpha=1}=\frac{1}{N} \sum_{i=1}^{N}\left(\frac{x_{i}}{\bar{x}} \cdot \ln \frac{x_{i}}{\bar{x}}\right),
$$

where $x=$ income/person.

To determine the statistical significance of changes between years in Gini or Theil's $T$ indices, we used a statistical package in Stata 12/SE (ineqerr) to calculate the mean Gini coefficient and Theil's $T$ index, standard error, and bias corrected confidence intervals for each year using the bootstrapping technique (100 repetitions; (Escudero and Gasparini 2000)).

\section{Herding economy survey}

In 2010, a single semi-structured interview was conducted with the managing head of household of the majority of families in our study $(n=27)$ to evaluate decision-making and herding strategies among families (some families were unavailable during this time due to migration). We recognize that missing some families due to migration may introduce bias into our results for this survey. However, it is extremely common in the pastoralist literature to find missing data points in some analyses due to migration, loss of follow-up, and subject refusal to participate, among other reasons. Furthermore, the requirements set by the Institutional Review Board on the treatment of ethical subjects requires researchers to exclude any data from subjects who do not give their permission to participate in a particular assessment, measurement, or questionnaire. Therefore, it is possible that all research on human subjects includes some bias if ethical principles and rules of conduct are respected accordingly.

We asked a range of quantitative and short answer, qualitative questions regarding herd structure and composition, shared herding and herding labour, herd splitting, breeding, migration, risks to herd survival (disease, theft, predation), renting of grass and squatting in absentee land, and herd decisions during drought. The answers from these surveys were then converted into binary $(0,1)$, ordinal, and continuous data for analysis. We then used this data to determine if a herder's decision-making pattern differs by wealth class. Qualitative data derived from this survey was also used to inform quantitative results regarding herding decisions and to better understand the perceptions of herders regarding local herding opportunities and constraints in Mukugodo.

\section{GIS tracking of livestock and statistical analysis of spatial} relationships among wealth classes

This part of the study focuses on the movement patterns of livestock herds in a normal rainfall year (2010). We chose to sample only goatherds, since their uniformity in grazing meant that We could control for forage preference differences among members of a herd. We chose to sample herds based on neighbourhoods: one large neighbourhood in Tiamamut and two smaller ones in Ilmotiok. Within these neighbourhoods, We opportunistically captured data on families of different herd sizes and wealth classes; families in a neighbourhood were often, but not always, related to each other. Overall, data was compiled on 4 rich families and 11 poor/middle class families. Six of these families lived in Tiamamut and eight in Ilmotiok. Each herd we sampled was managed as a single unit, either by a single house and herder or as part of a meta-household.

To obtain accurate data on movement, we affixed GPS collars (Savannah Tracking Ltd, 2012) on a single adult animal from each herd. Herders were given the right to choose which animal the collar was fixed to within their herd. Each herd was monitored with a GPS collar for an average of four consecutive days. Herds rarely if ever fragment during grazing bouts, so a single animal's behaviour was assumed to be representative of the overall herd's behaviour and location. The GPS collars obtained point fixes every $15 \mathrm{~min}$, capturing general movement parameters rather than micro movement data. Due to the limited number of collars available for sampling (2), each herd was monitored twice during the course of a seven-month field season in 2010.

All GPS data collected from herds was processed into tracks using ArcGIS 9. Many GPS fixes were taken before and after grazing when the animals were confined to the boma (livestock enclosure or corral). We visually inspected each herd track in GIS to detect and remove these spurious points manually. Using ArcGIS, We calculated the daily distance to water, herding radius, and maximum distance travelled for each grazing path. The distance to water is defined as the shortest distance to a water point from the start of the herding path, i.e. the homestead. The herding radius is defined as the single furthest distance travelled by the herd from the homestead (often this point is the water source). 
Subsequent analysis of spatial data was performed in ArcMap (version 10, 2011) and Stata 12/SE.

All other statistical analyses found in this paper were performed with packages in JMP 9 (SAS Institute 2011) and Stata 12/SE (Stata Corporation 2011).

\section{Results}

Short-term rainfall and forage dynamics in IImotiok and Tiamamut group ranches

Annual rainfall values ${ }^{7}$ for the Ilmotiok and Tiamamut group ranches indicate that 2007 and 2008 were relatively dry years. Rainfall reached its lowest levels during the drought in 2009 (Figures 3 and 4). Total rainfall values in 2010 (recovery year) and 2011 (unusually wet year) were approximately three times that of 2009. In 2012, rainfall failed completely during the first part of the year, artificially increasing the dry period by one month (no rainfall events in March 2012). However, rainfall levels recovered substantially in April and May, with over $100 \mathrm{~mm}$ of rain during this key period, indicating that 2012 should be a wet year as well.

NDVI values over the same period (2007 to 2012) indicate that when rainfall levels increase, forage levels ('greenness') also increase but with a one-month lag. As shown in Figure 5, NDVI peaks one month after a significant rainfall event. This indicates that pastoral families must wait for at least one month after the rains start to see significant improvements in the productivity of their livestock. Herds need about one month of feeding on improved pastures to improve the amount of milk each animal produces during that period. As such, livestock quality is improving as the grass greens up; however, rainfall must be frequent for this trend to continue.

An analysis of the correlation between the timing of rainfall events, NDVI, and livestock productivity (Figure 6) indicates that about one month after it rains, forage levels improve and milk production responds immediately. This effect carries over for one month, meaning that even if it does not rain again for a month, households will have enough forage to maintain production levels for one month. After two months, milk production falls by nearly half if it does not rain again (from $R^{2}=0.65$ to $R^{2}=0.4$ ). This represents a safety net for households in that they do not have to split their herds immediately when the rains fail but can wait and allow for their families to uptake the milk before moving off again.

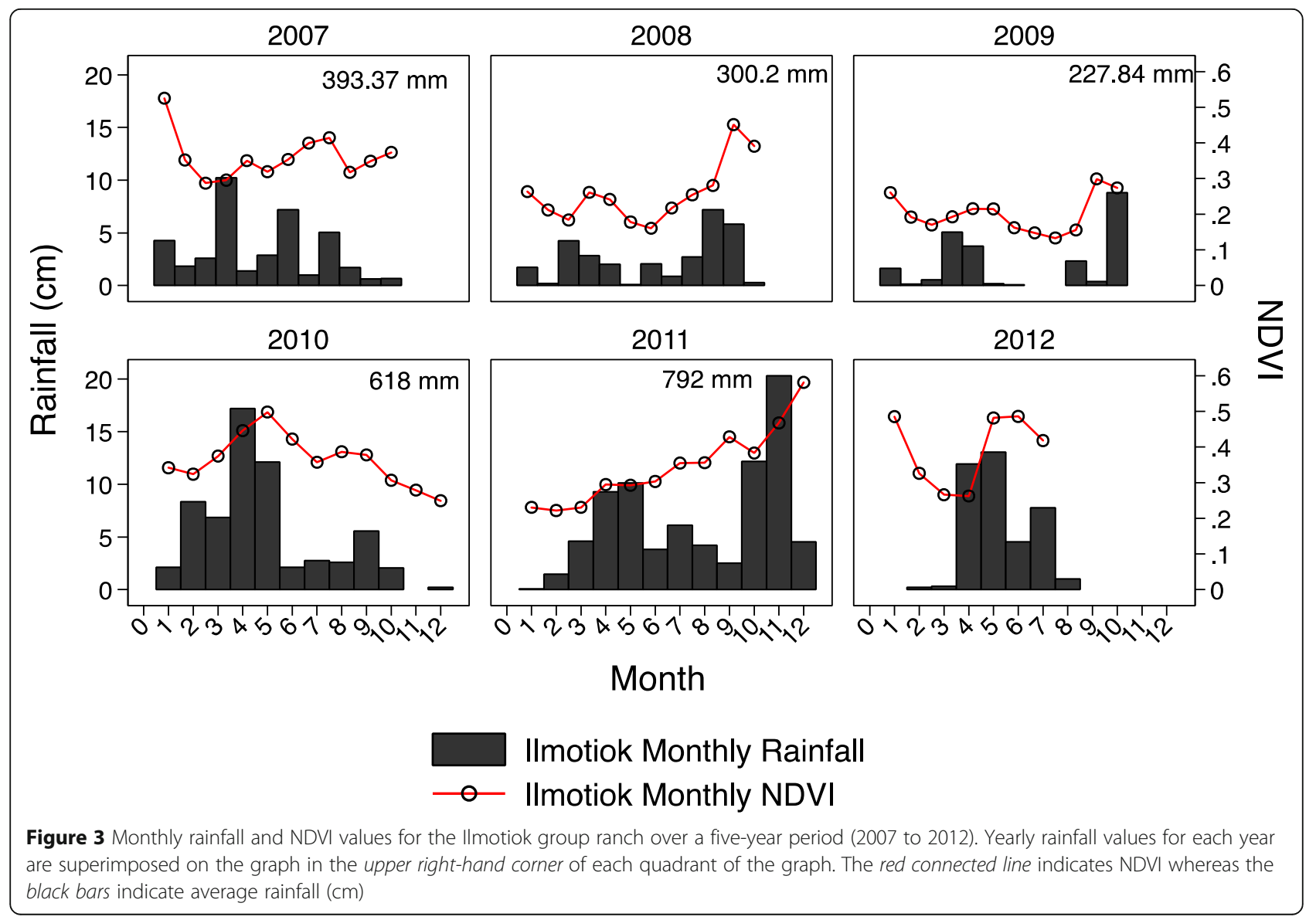



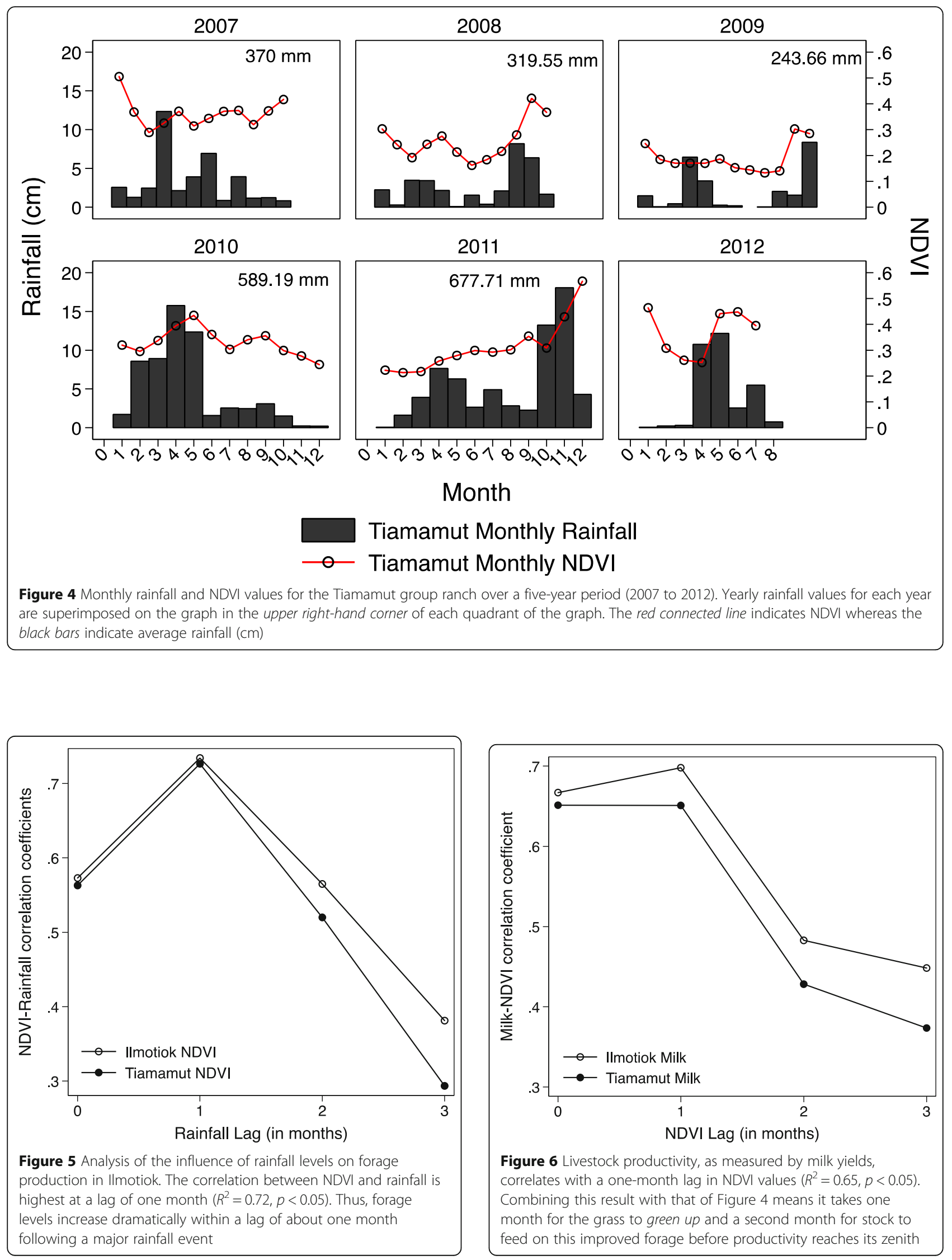

Figure 6 Livestock productivity, as measured by milk yields, correlates with a one-month lag in NDVI values $\left(R^{2}=0.65, p<0.05\right)$. Combining this result with that of Figure 4 means it takes one month for the grass to green up and a second month for stock to feed on this improved forage before productivity reaches its zenith 
Long-term trends in Laikipia's northern rainfall dynamics: The case of Ilmotiok and Tiamamut

Annual rainfall values from northern Laikipia, Kenya, indicate that this region has undergone a progressive reduction in rainfall values over time (Figure 7). In the 1960s, droughts were strongly episodic, with one drought occurring every four years (1961, 1965, 1969). This pattern changes in the 1970s, starting with a threeyear drought from 1971 to 1974 and a second drought after only one year in 1976. The 1980s are then relatively stable, with a similar drought cycle as the 1960s (1980, 1985, 1987, 1989), although the pattern deteriorates as we enter the 1990s. From 1991 onward, there is only one year where the average rainfall is over $300 \mathrm{~mm}$ (1998). When we aggregate the rainfall data by 16 -year quadrants and calculate the coefficient of variation $(\mathrm{CV})$ between quadrants (Figure 8), we find that CV is trending up over time (from 0.2 in Q1 to 0.4 in Q3); however, this increase was not statistically significant $(p<0.08)$.

Our historical rainfall pattern suggests that this region is becoming progressively drier and more drought-prone over time. This assertion is further demonstrated in Figure 9, where a fitted LOWESS (Cleveland 1979) curve of rainfall against year clearly shows a sharp decline in rainfall values at or near 1990. As indicated by the LOWESS curve, median rainfall decreases by almost $50 \%$ over the 30 -year period.

\section{Trends in forage generation using long-term rainfall and NDVI values}

As indicated in Figure 10, NDVI or 'greenness' increases linearly with rainfall. There is a statistically significant correlation between NDVI and rainfall (at a lag of one month) indicating an improvement in forage availability during this time frame $\left(R^{2}=0.40, t(11,311)=85.9, p=\right.$ $0.000)$. These regression results, when paired with a Pearson product moment correlation of 0.39 (CI 0.370 to 0.403 ) indicates that our lag of 31 days sufficiently predicts the historical process of green up in these communities. However, a lag of 31 days more accurately predicts green up in the restricted twenty-first century subset (2007 to 2012) of data, with a higher correlation coefficient $\left(R^{2}=0.72, p<0.05\right)$ than the 30 -year data set.

\section{Mobility patterns: How do families deal with a mixed land use system?}

Herders make decisions about where to migrate with their livestock based on a variety of social and ecological

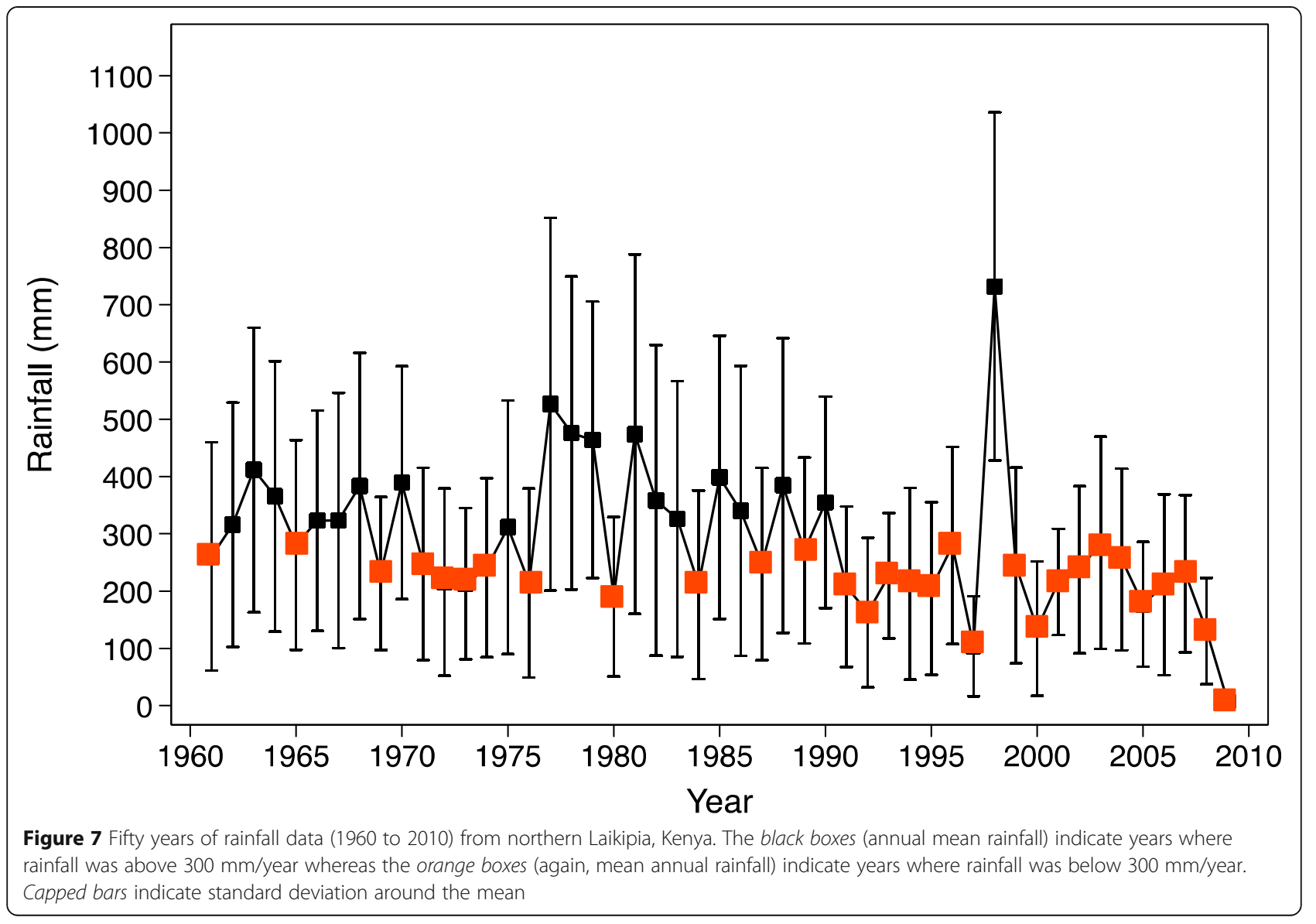




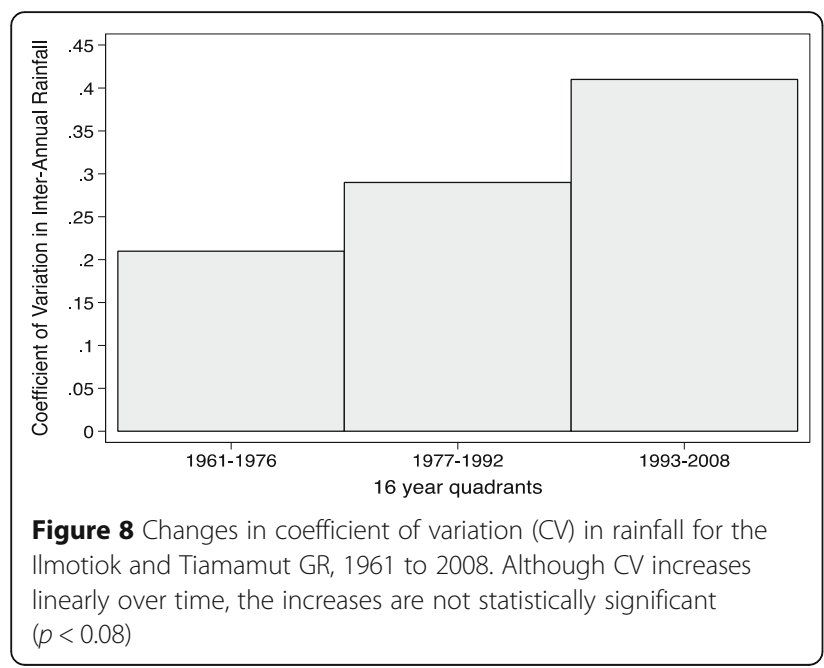

factors. Here we generated a map of Laikipia County (see Figure 11) with each land parcel labelled according to its status (private, public, communal). Superimposed over this structure are public access roads and government-designated cattle tracks. Our two group ranches (Ilmotiok and Tiamamut) are located in the upper

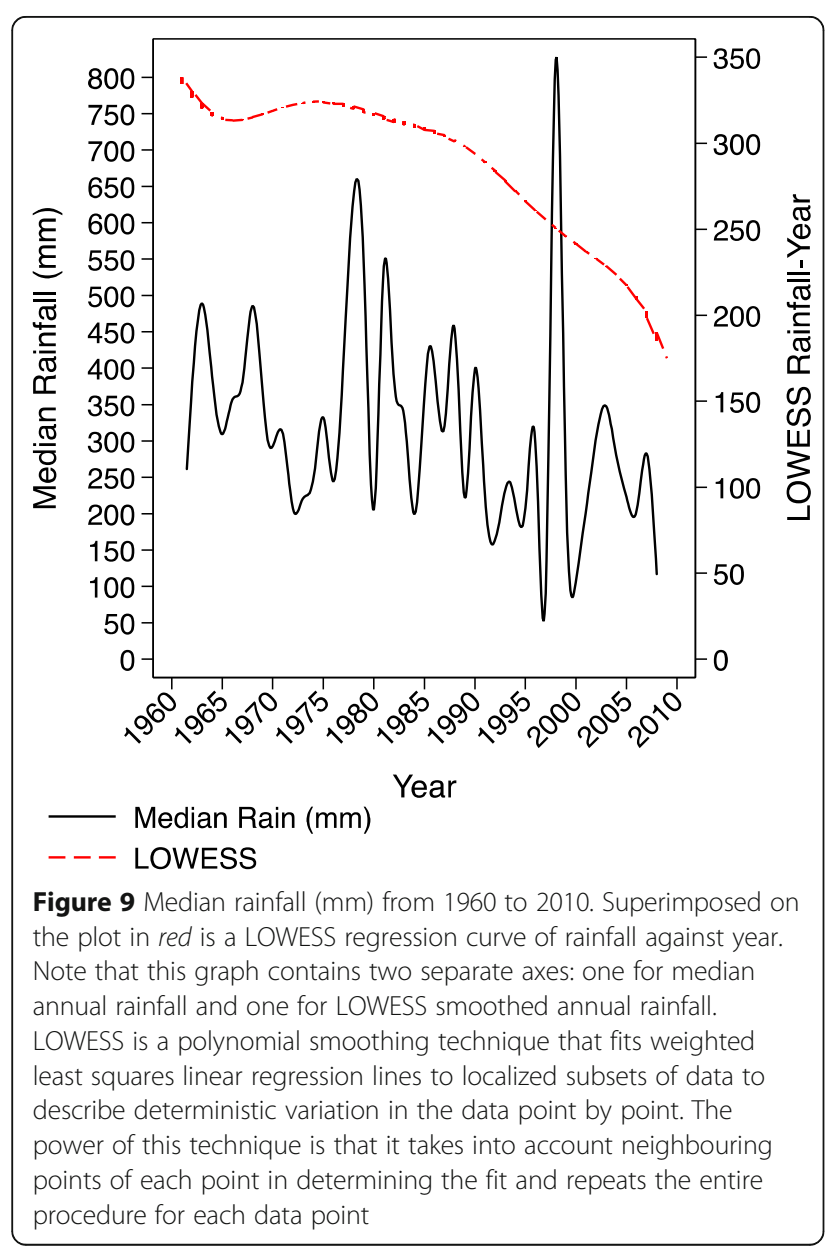

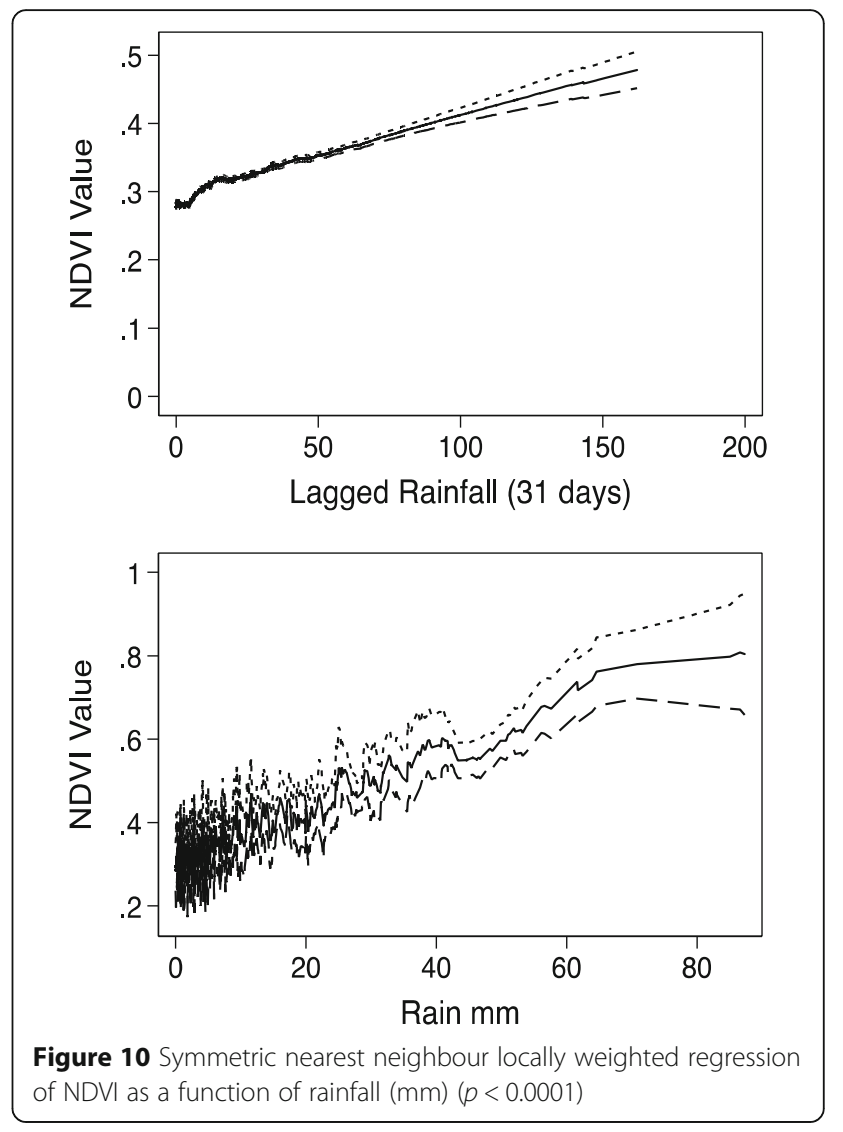

right-hand corner of the map in the patch of green land parcels designated by the government in the 1970s as communally managed lands. They directly abut a large swath of private ranches and farms, many of which (such as Mpala and Ol Jogi) are engaged in endangered species conservation. Public lands dominate the western and southern portions of the county, where lands have been cut up into many tiny parcels, most of which are owned by absentee landowners. Many of these lands are not fenced, making them easily accessed by migrating herds.

A few places stand out in the map. There are two communally managed lands - P\&D and N/Approach - that offer 'safe zones' near frequently used squatter patches (such as Endana, near N/Approach and P\&D near Kirimun; see Figure 12). Squatter patches are abandoned patches of land that are occupied by pastoralists for the purposes of grazing without seeking permission from land owners or paying a rental fee for use. Some absentee lands offer safe squatting grounds near other patches, such as Mathira 2 being a holding ground for Segera and Karashira as a holding ground for the Rumuruti approach to the Aberdare Mountains near Mifugo. Public roadways from communal lands through private lands provide access to public lands where pastoral families set up temporary camps for grazing during dry seasons (Hauck, personal observation, 2008 to 2011). Roads are 


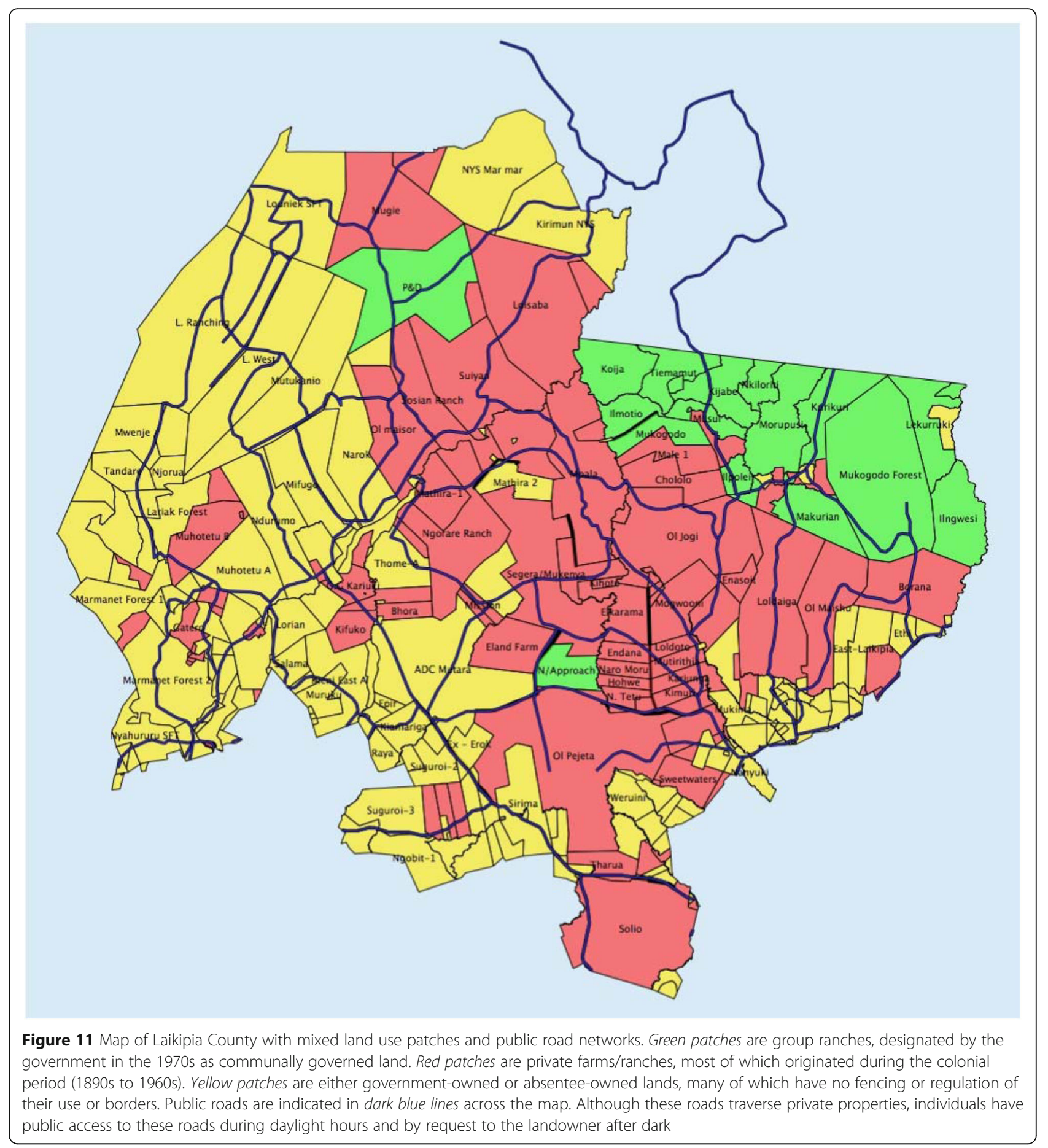

only accessible during daytime hours, so herders requiring nighttime transit through private ranches must negotiate those access rights in advance (Mike Littlewood, personal communication, 2011).

Private ranches usually charge a grass rental fee to herders from off property. The fee ranges from $50 \mathrm{KsH}$ (50 cents) per head of cattle (Loisaba) to $200 \mathrm{KsH}$ (\$2.00 dollars) per head of cattle (Mpala). This rental fee also includes the provision of labour to herd the cattle. This is particularly important for poor herders, who generally have one or two cows but do not have the necessary labour to send them for off group ranch grazing. In effect, ranches like Mpala provide herders with subsidized grass and labour for cattle during dry seasons and droughts. All private ranches accept cattle as renters. However, in extreme cases (at 


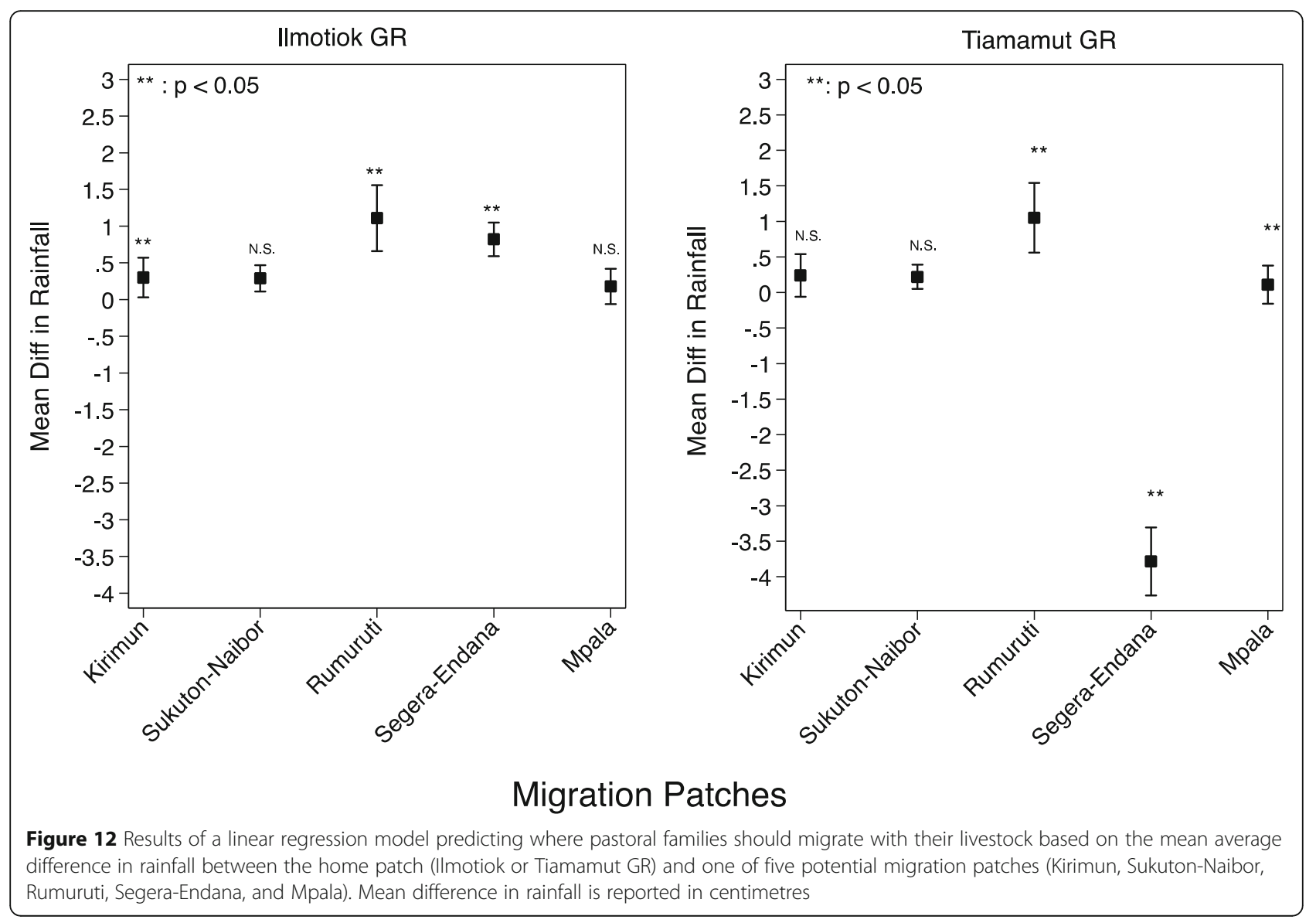

Mpala only), a few herders may be able to negotiate access for sheep herds who are highly dependent on grass. Private ranches also place limits on the number of livestock that are accepted on their property, usually accepting no more than 100 from a given group ranch. Public lands, on the other hand, are usually unmonitored, so herders can travel to these patches and squat without having to pay rent for the grass they consume. Many herders from around the region use these squatter patches, so they are plagued by theft and banditry, making them unsafe for herders living there. For example, raiders stealing cattle gunned down the local chief's son in one of these squatter patches. Although unsafe, these patches are important since they accommodate all species, even goats, which the private ranches will not accept for grazing.

Our results indicate that based on rainfall differences alone, herders in Ilmotiok should migrate to one of three places: north to Kirimun, where rainfall is $0.2 \mathrm{~cm}$ higher; southwest to Rumuruti, where rainfall is $1 \mathrm{~cm}$ higher; and south to Segera-Endana, where rainfall is about $0.7 \mathrm{~cm}$ higher (Figure 12). On the other hand, herders in Tiamamut should ideally all migrate to Rumuruti, since that is the only migration patch with significantly improved rainfall (approx. $1 \mathrm{~cm}$ higher). Mpala is the only other patch with significantly different rainfall than Tiamamut. Grazing on Mpala, however, is only open to those renting grazing for cattle, so goat and sheep herds are generally not allowed in, except under extreme duress. Herders from Tiamamut should not migrate to Kirimun, Sukuton-Naibor, or Segera-Endana based on rainfall differences, since rainfall and, therefore, vegetation conditions are likely to be similar if not worse on average than in the home patch. Results of analyses of livestock movement records from 2008 to 2011 indicate that there are significant differences between group ranches in where they move their livestock during dry seasons or droughts to access forage and water resources, with a few exceptions.

In $2008,44.5 \%$ of Ilmotiok herders reported moving their cattle to Mpala vs. $25 \%$ of Tiamamut herders $\left(\mathrm{chi}^{2}=\right.$ 14.11, $p<0.227$ ), but the difference was not statistically significant. Similarly, 37\% of both Ilmotiok and Tiamamut herders migrated to Sukuton in 2008. Tiamamut herders report migration to other areas in 2008, such as Endana $(12.5 \%)$, Fois (6.25\%), and Koija (6.25\%). Herders in 
Ilmotiok do not cite using any other outside patches during this year; however, they do cite moving stock to affines or relatives in other neighbourhoods in their own group ranch to acquire grazing access (Lorubay or Naserian). Herders who moved their stock to Mpala (Tiamamut) during this period behaved in accordance with our prediction based on ecological factors.

In 2009, there are significant differences between Ilmotiok and Tiamamut herders regarding migration location (Ilmotiok vs. Tiamamut; $\mathrm{chi}^{2}=46.05, p<0.002$ ). Tiamamut herders report migrating to a wide range of different grazing patches. $9.75 \%$ report migrating to Endana and Mount Kenya, whereas 17\% report migrating to Kiperen (Mpala/Soit Nyiro property line), $15 \%$ to Sukuton, and $9.75 \%$ report sending their cattle to Mpala. Ilmotiok herders move their animals to similar locations but with different frequency. $10 \%$ of families report making local migrations within Ilmotiok (from their home boma to an affine's or relative's boma). 34.33\% report migrating to Kiperen, and $26.8 \%$ sent cattle to Mpala. In contrast to 2008, Ilmotiok families report migrating to a few patches that Tiamamut herders do not report using: $2 \%$ to Loisaba Wilderness, $2 \%$ to Ngabolo, $5 \%$ to Male Ranch, and 3\% to Maraka Farm. Herders from Tiamamut that moved their stock to Kiperen, Mpala, and Segera acted in accordance with our predictions. Similarly, herders from Ilmotiok who moved their herds to Loisaba and Ngabolo (near Kirimum) acted in accordance with our predictions.

In 2010, there are again significant differences between group ranches regarding migration behaviour (Ilmotiok vs. Tiamamut; $\mathrm{chi}^{2}=15.023, p<0.020$ ). First of all, the number of locations that herders report migrating to with their livestock is significantly reduced from 2009 to 2010 (23 vs. 7, respectively). Here the majority of Ilmotiok herders report moving livestock back to their home patch (37\%), to Ngabolo (36\%), or to Sukuton (18\%). In contrast, $31 \%$ of Tiamamut herders report moving to Fois, $16 \%$ to Ivan's farm, $39 \%$ to Sukuton, and $8 \%$ to Ngabolo and Tiamamut. Note that only $8 \%$ of Tiamamut herders report returning livestock to their home patch vs. $37 \%$ of Ilmotiok herders. Here Ilmotiok herders are making very good decisions based on our predictions by moving their stock to Ngabolo, but not by moving them to Sukuton. Similarly, herders from Tiamamut are making good decisions by migrating to Fois, which is next to Segera-Endana and Ivan's, which is next to Mpala.

Lastly, in 2011, herders continue to report herd migrations, but once again, the number of sites listed as being used is reduced from seven to five. Eighty-five percent of Ilmotiok herders report sending cattle to Mpala for rented grass and 15\% reported moving any remaining livestock back to Ilmotiok. Tiamamut herders report using three different patches during this year equally: 33\% to Kere Farm, 33\% to Muhammad Farm, and 33\% to Sukuton. These differences are statistically significant $\left(\mathrm{chi}^{2}=10.0, p<0.04\right)$. Here neither set of herders seems to be moving stock based on rainfall differences alone.

\section{Wealth inequality in pastoral families}

Using the linear expression described in the 'Methods' section, we calculated Lorenz curves using the income distribution of our sample families for each year of the study (2008 to 2011). Deep convexity in the overall distribution of incomes in our population indicates that incomes and assets are highly unequal, with three to four families controlling approximately $50 \%$ of the wealth (see Figure 13 ).

Similarly, by plotting a different curve for each year, we can establish that wealth inequality contracts during poor rainfall years and expands during the first year following a drought. Our 2008 curve is assumed to be the quasi-'normal' distribution of incomes during normal years of rainfall and forage accumulation. In 2009, which was one of the worst droughts in the Horn of Africa in 100 years, incomes actually contract, moving more towards the equi-distribution line, meaning that everyone was affected by some loss during the drought, even the rich at the far right of graph. Most

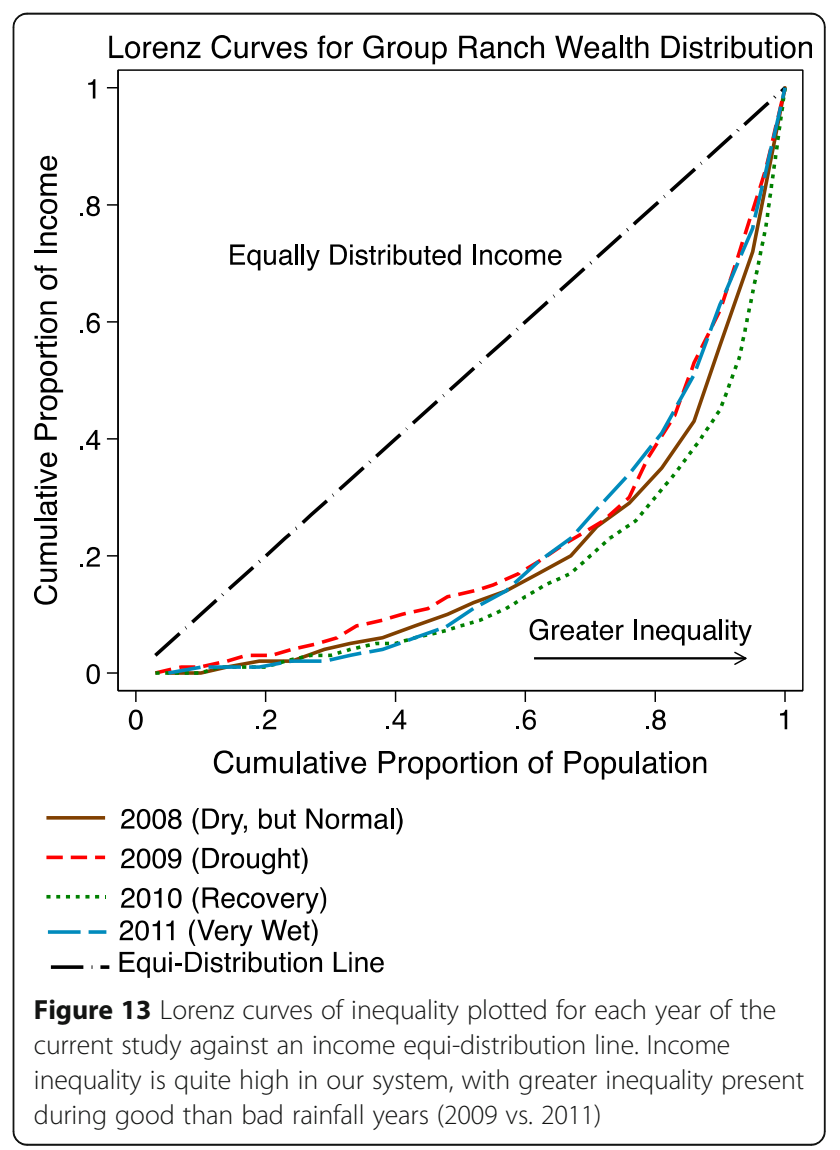


interestingly, in 2010, income equality expands dramatically from 2009, with the richest families controlling the largest percentage of incomes during the recovery year. In 2011, the curve starts to return to 2008 levels but is actually less convex than 2008 on the upper half of the curve. This indicates that inequality contracts as the system moves away from crisis years and recovery years to more normal conditions.

Using both Theil's $T$ and the Gini coefficient as our statistical markers of inequality, we can determine that incomes are highly unequal overall, with both high $T$ and Gini values for all years (Figure 13). During 2008 and 2009, inequality values were roughly equivalent, with no significant change between years ((for example, mean Gini in 2008 of $0.56,95 \% \mathrm{CI}(0.413$ to 0.634$)$, vs. mean Gini in 2009 of 0.55 , 95\%CI (0.466 to 0.627$)$ ), which may reflect the universality of drought loss for families at all income levels during this period). In 2010, however, income inequality expands dramatically in both markers (see Figure 14 for numerical Gini and Theil's $T$ values and standard error) and then declines precipitously in 2011 to pre-drought levels. This extreme shift in inequality may be due to differential access to livestock via paran (social obligation or exchange) or cash assets to re-purchase lost stock. The results of these two indices agree with our overall visual interpretation of the Lorenz curves (Figure 13).

\section{Migration choices during drought: Rich vs. poor and middle class herders}

Results of a questionnaire completed in May 2010 with each male or female head of household in our study $(n=$ 30) reveal some factors that act to differentiate herding decisions based on wealth, with some minor exceptions.

Results of our interviews with herders revealed that $95 \%$ of the poor and middle class families named rights of access to pasture as the most important feature defining movements during droughts $\left(\mathrm{chi}^{2}=3.85, p<\right.$ 0.05 ), second only to the risk of moving a herd to an area that is already devoid of grazing by the time they arrive $\left(\mathrm{chi}^{2}=3.85, p<0.05\right)$. Lower status families report having difficulty negotiating rights of access to certain areas even if they can acquire information about forage quality in more distant patches; in effect, ability

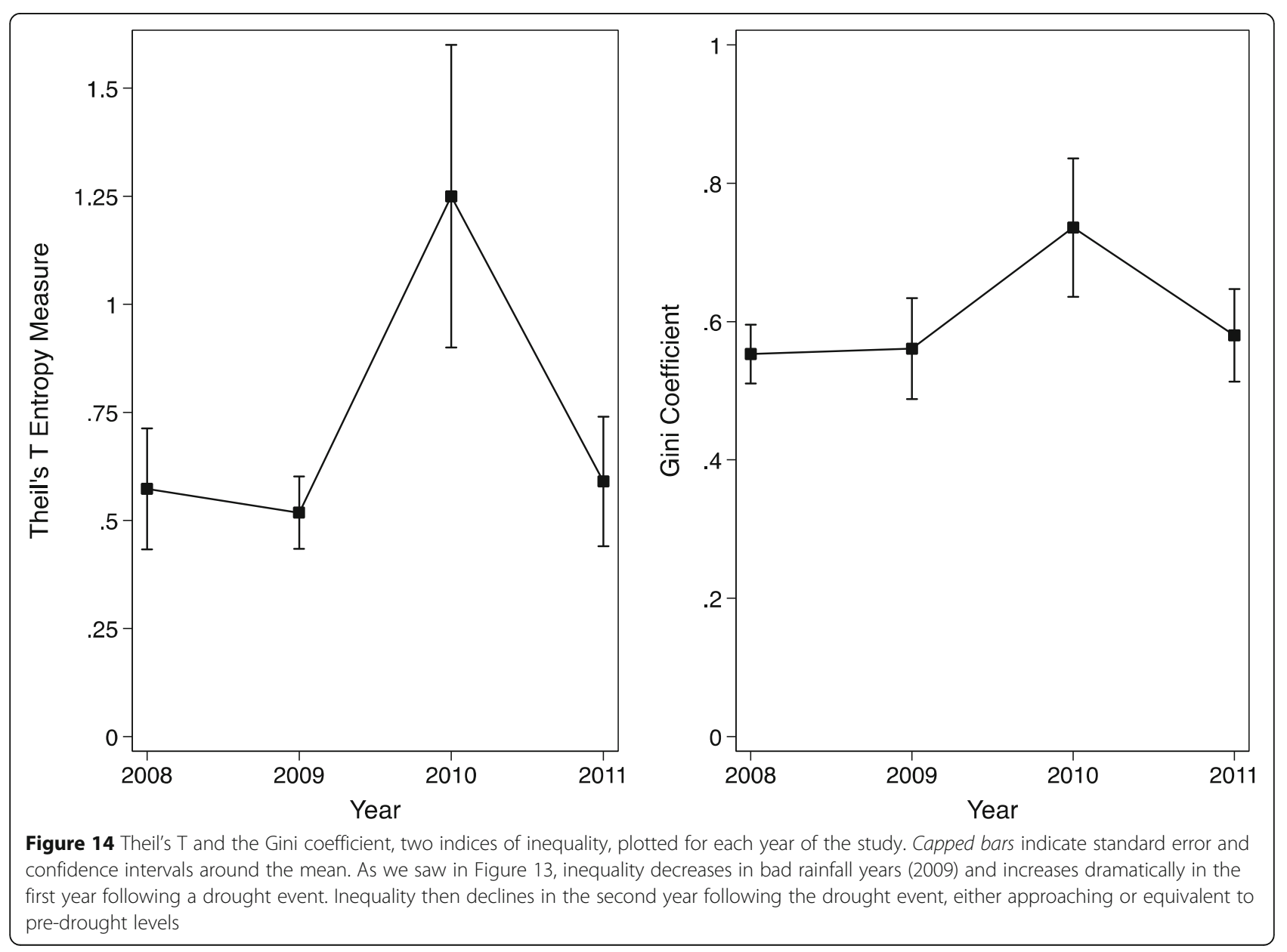


Table 3 Results of Pearson product-moment correlation analysis between rich and poor/middle class herders on migration patch use during the 2009 drought year

\begin{tabular}{lllcc}
\hline Migration patch & Rich (\% using) & Poor/middle (\%using) & Pearson chi $^{2}$ & 0.09 \\
\hline Kiperen & 50 & 43 & chi $^{2}$ \\
Sukuton & 50 & 62 & 0.27 & 0.75 \\
Mount Kenya & 50 & 24 & 1.53 & 0.6 \\
Endana & 17 & 33 & 0.62 & 0.21 \\
Mpala (rent) & 17 & 19 & 0.01 & 0.43 \\
Eluai & 17 & 0 & 3.63 & 0.89 \\
Koija & 17 & 0 & 3.63 & 0.05 \\
Rumuruti & 17 & 5 & 0.96 & 0.05 \\
Fois Robo & 17 & 5 & 0.96 & 3.63 \\
Karashira (Rumuruti) & 17 & 0 & 3.63 & 0.33 \\
Ngarenyiro (Rumuruti) & 17 & 0 & 0.05 \\
\hline
\end{tabular}

The male or female head of each household enrolled in the study was interviewed regarding drought season herd migrations in May 2010

to migrate is half the battle. Moreover, reduced competition for grazing, induced by rich families fleeing the system for exclusive access patches when resources are depleted, means that poor and middle class families can utilize residual grazing in their home patches until it rains again. In theory, poor families who stay in the home patch should be the first to benefit from improved local forage when the rains return.

In general, rich and poor/middle class families report using similar migration patches during the drought (in particular, Sukuton, Mount Kenya, Endana, and Mpala; see Table 3). However, rich families access a number of exclusive migration patches or grazing easements that poor families did not use or have access to (Eluai, Koija, Karashira, Ngarenyiro).

\section{Local movement patterns: Group ranch and wealth-related differences}

For those herds that remain locally, we found significant differences between group ranches on two key herding parameters: maximal distance to water and herding radius. There was no significant difference between wealth classes (HL estimator 31.7 meters, ns) or group ranches (HL estimator 847.3 meters, ns) in maximum herding distance. We do, however, observe a trend in the data that suggests herders in Tiamamut travel shorter maximum herding distances than herders in Ilmotiok (mean difference 847.3 meters; almost $1 \mathrm{~km}, p<0.07$ ).

When we pool the data on group ranches together, significant differences emerge between rich and middle class families regarding two key aspects of herding strategy. There were consistent differences between rich and poor/middle class herders in maximal distance to water and herding radius (see Tables 4 and 5 and Figures 15 and 16). Poor herders travelled longer maximal distances to water (864 meters) and used a larger area (400 meters) to complete their herding path. These two parameters were significantly different between the two group ranches as well as the different wealth classes. Ilmotiok herders consistently travelled longer distances to water (903 meters) and had longer overall herding radii (1439 meters).

\section{Livestock productivity as a function of 'greenness' (NDVI)}

Here we use milk availability as our variable of livestock productivity. Specifically, we use the amount of milk available to a household for human consumption after calves, kids, or lambs have been fed. Regression analysis of the fit of milk availability by NDVI (Figure 17) indicates that milk availability significantly increases for all livestock species when greenness levels increase, with the highest overall yields $(1,250 \mathrm{ml}$ per family/day $)$ at

Table 4 Results of Mann-Whitney $U$ test with Hodges-Lehmann effect (HLE) size estimator (between Ilmotiok and Tiamamut group ranches)

\begin{tabular}{|c|c|c|c|c|c|c|}
\hline \\
\hline \multicolumn{7}{|c|}{$\begin{array}{c}\text { GIS data results of differences between llmotiok and Tiamamut group ranches in local herd movements } \\
\text { IImotiok Mean } \pm \text { SD } \quad \text { Tiamamut Mean } \pm \text { SD } \quad \text { MW }\end{array}$} \\
\hline Parameter & & & $U$ & $z$ & p & HLE \\
\hline Maximal distance to water $(\mathrm{m})$ & $2,973.64 \pm 776$ & $1,785.43 \pm 736.21$ & 1,708 & 4.418 & 0.0000 & -903.6 \\
\hline Herding radius (m) & $2,786.31 \pm 762.78$ & $1,906.03 \pm 723.43$ & 1,757 & 5.1 & 0.0000 & $-1,439$ \\
\hline Maximum herding distance $(\mathrm{m})$ & $7,313.71 \pm 1896.2$ & $6,537.66 \pm 1386.27$ & 1,518 & 1.811 & 0.0700 & -847.3 \\
\hline
\end{tabular}


Table 5 Results of Mann-Whitney $U$ test with Hodges-Lehmann effect (HLE) size estimator (between rich and poor/middle class families)

\begin{tabular}{|c|c|c|c|c|c|c|}
\hline & & Poor/middle Mean & MW & & & \\
\hline Parameter & Rich mean $\pm S D$ & Poor mean $\pm S D$ & U & $z$ & $p$ & HLE \\
\hline Maximal distance to water $(\mathrm{m})$ & $2,000.48 \pm 740.61$ & $2,691.37 \pm 950.22$ & 252 & -2.909 & 0.0036 & 864.74 \\
\hline Herding radius (m) & $2,092.21 \pm 774.32$ & $2,570.48 \pm 855.33$ & 279 & -2.46 & 0.0014 & 400.69 \\
\hline Maximum herding distance $(\mathrm{m})$ & $7,035.94 \pm 1,305$ & $7,039.9 \pm 1,869.3$ & 424 & -0.082 & 0.9340 & 31.7 \\
\hline
\end{tabular}

NDVI values of 0.4 and above $(2313.852, t(560)=5.30$, $p<.0001)$.

\section{Species specific analysis of herd productivity by wealth and year}

As shown in Table 6 below, small stock milk production differed significantly by year (2009, 2010, and 2011; all $p<0.001$ but not 2008 , n.s.) as well as by wealth rank (rich vs. poor; $p<0.001$ ). There were also significant interactions between year and wealth rank, with higher milk outputs for poorer families in 2008 and richer families in 2009 and 2010. Similarly, increases in small stock output indicate commensurate increases in small milking stock (small LLU: individuals switching from breeding to lactating; $p<0.001$ ) in the herd. The overall model explains roughly $67 \%$ of the variation we see in small stock milk yields $\left(R^{2}=0.67\right.$, $F(8,79)=19.74, p<0.0000)$.

In Table 7, we present similar results for large stock milk availability (camels and cattle). Large stock milk yields decreased sharply in 2009 and $2010(p<0.001)$, with year being a statistically significant predictor of decreases in milk yield. Wealth rank was also a significant predictor of reductions in milk yield by year, with rich families seeing the greatest reductions in

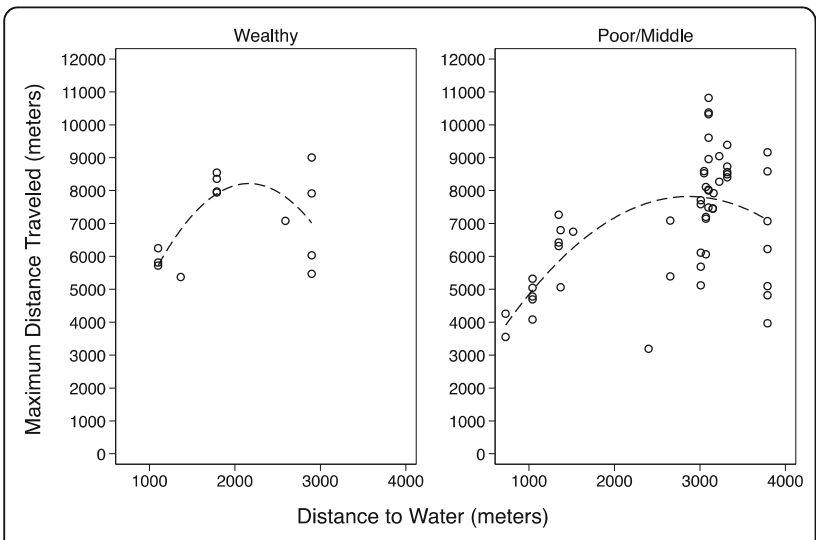

Figure 15 Quadratic fit of maximum distance travelled as a function of maximal distance to water by wealth rank. Wealthy families travel shorter distances to reach water, meaning they spend less time trekking to water and more time grazing milk yield in $2009(p<0.05)$ and $2010(p<0.001)$. Lactating herd size was not a significant predictor of milk availability for large stock species $(p>0.05)$. The overall model was statistically significant, explaining approximately $80 \%$ of the variation we observe in large stock milk yields $\left(R^{2}=0.80, F(7,14)=7.94, p<0.0006\right)$.

Considering that wealth rank and year are significant predictors of milk yields for subsets of livestock species managed by each household, we ran a regression analysis to determine if total milk available per capita was significantly different among households by year or wealth class, controlling for family size. Total milk yield available was significantly higher among years for wealthy families, except for 2008 where rich families have less access to milk than poor or middle class families $(p>0.05)$. Poor families suffered statistically significant decreases in milk yield during the drought year (2009), when compared to wealthier families $(p<0.05)$ (Figure 18).

In 2008, rich families reported very low per capita milk yields $(101.30 \mathrm{ml} \pm 5.03)$ whereas poor/middle class families reported higher per capita milk yields $(344.08 \mathrm{ml} \pm$ 5.35). During the drought year, both sets of families report per capita yield less than $200 \mathrm{ml}$ (rich $178 \mathrm{ml} \pm 4.72$; poor/ middle $122.71 \mathrm{ml} \pm 2.41$ ). In 2010, differences in milk yield

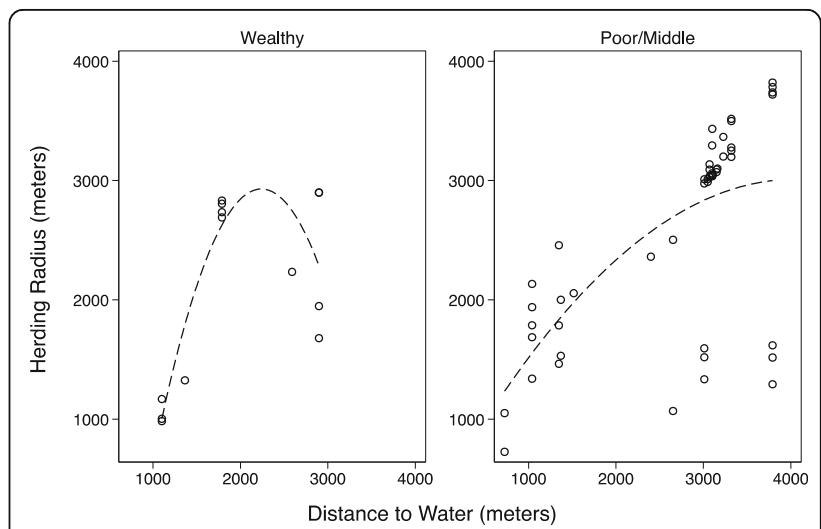

Figure 16 Quadratic fit of herding radius as a function of maximal distance to water by wealth rank. Wealthy families travel shorter distances to complete their grazing circuit before returning home. They can do this since they spend less time trekking their herds to water 


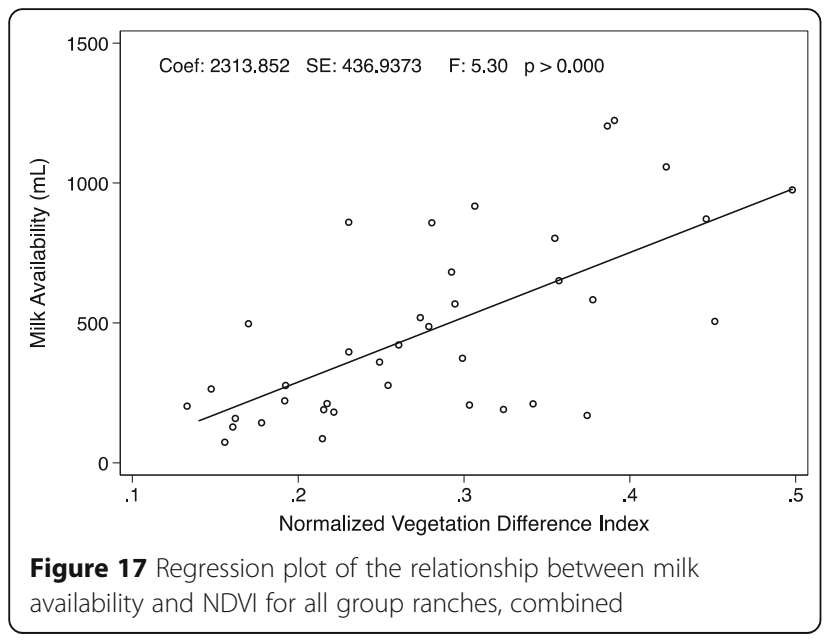

between rich and poor emerge, with rich families reporting an average of $503.42 \mathrm{ml} \pm 8.48$ and poor families reporting almost $50 \%$ less $(296.17 \mathrm{ml} \pm 3.58)$. In 2011 , rich families report consuming $1,720 \mathrm{ml} \pm 41.47$ of milk per day whereas poor and middle class families are still consuming per capita amounts less than $200 \mathrm{ml}$ per day

Table 6 Results of linear regression of small stock milk yield (per capita availability for human consumption), adjusted for lactating herd size and family size

\begin{tabular}{|c|c|}
\hline Predictor variable & Outcome: small stock milk/capita \\
\hline \multirow[t]{2}{*}{2009} & 589.481 \\
\hline & $5.25^{* *}$ \\
\hline \multirow[t]{2}{*}{2010} & 748.148 \\
\hline & $6.67^{* *}$ \\
\hline \multirow[t]{2}{*}{2011} & 675.488 \\
\hline & $6.30^{* *}$ \\
\hline \multirow[t]{2}{*}{ Wealth rank } & -544.297 \\
\hline & $5.48^{* *}$ \\
\hline \multirow[t]{2}{*}{$2008^{*}$ rank (poor) } & 704.832 \\
\hline & $6.19^{* *}$ \\
\hline \multirow[t]{2}{*}{$2009^{*}$ rank (rich) } & -544.542 \\
\hline & $5.05^{* *}$ \\
\hline \multirow[t]{2}{*}{$2010^{*}$ rank (rich) } & -696.351 \\
\hline & $6.27^{* *}$ \\
\hline \multirow[t]{2}{*}{ Small LLU } & 156.660 \\
\hline & $8.52^{* *}$ \\
\hline \multirow[t]{2}{*}{ Intercept } & -96.481 \\
\hline & 1.81 \\
\hline$R^{2}$ & 0.67 \\
\hline N & 88 \\
\hline \multicolumn{2}{|c|}{$\begin{array}{l}\text { Significant predictor variables were year, wealth rank, and total lactating herd } \\
\text { size. Values reported in the table are beta coefficient and } t \text { value. The asterisks } \\
\text { indicate degree of significance } \\
\text { LLU lactating livestock unit } \\
{ }^{*} p<0.05 ;{ }^{* *} p<0.01\end{array}$} \\
\hline
\end{tabular}

Table 7 Results of linear regression of large stock milk yield per capita, adjusted for lactating herd size and family size

\begin{tabular}{ll}
\hline Predictor variable & Outcome: large stock milk per capita \\
\hline 2009 & -574.243 \\
& $5.28^{* *}$ \\
& -288.361 \\
& $2.48^{*}$ \\
2011 & -333.333 \\
& 1.92 \\
Rank & -600.699 \\
& $2.66^{*}$ \\
$2009^{*}$ rank (rich) & -580.933 \\
& $2.43^{*}$ \\
$2010^{*}$ rank (rich) & -813.974 \\
Large LLU & $3.25^{* *}$ \\
Intercept & 29.319 \\
$R^{2}$ & 0.86 \\
$N$ & $1,245.377$ \\
\hline
\end{tabular}

Significant predictor variables were year and wealth rank. Values reported in the table are beta coefficient and $t$ value. The asterisks indicate degree of significance

LLU lactating livestock unit

${ }^{*} p<0.05 ;{ }^{* *} p<0.01$

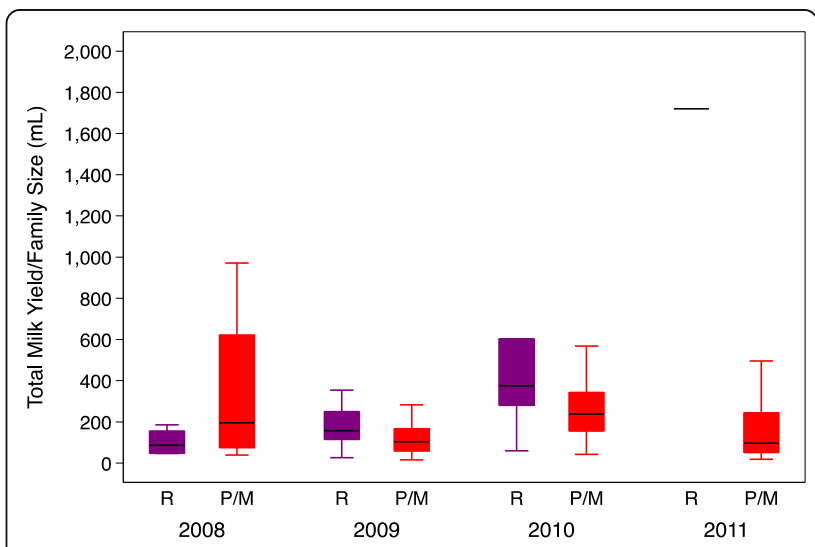

Figure 18 Total actual milk yields available per capita for all four years of the current study ( $n=31$ families). $R$ indicates 'rich' households and $P / M$ indicates 'poor and middle class' households. Data is plotted by year from 2008 to 2011. Yields are low for all four years among poor/ middle class families, with individuals having access to approximately $200 \mathrm{ml}$ per day. Milk yields only significantly improve for the rich in the years following the drought (2010 to 2011). Low sample size in 2011 among rich families did not allow for enough variation to calculate accurate standard error around the mean. Reported as (mean $+/$ - standard error) in the text below 
$(171.30 \pm 3.63)$. In 2011 , we were unable to accurately measure the majority of wealthy families in our sample due to loss of follow-up. Although we see a trend towards increased consumption of milk by rich families (Figure 17), there are no significant differences between rich and poor/middle class families in per capita milk consumption in $2011(U=14,1.612, p<0.10)$.

Differences between rich and poor/middle families in milk yields following drought may be due to differences in herd composition and lactation effort. In 2010, rich families held on average $77 \%$ of their lactation in small stock and 23\% in large stock. These lactating herd compositions are almost identical to those in 2009 (75:25 for rich, 77:23 for poor), indicating a slow return to 'normal' herd distributions following the drought. Poor families, however, held $90 \%$ of their lactation in small stock and $10 \%$ in large stock. These differences only increase in 2011, where rich families distribute their lactation efforts almost equally across species (small stock 42\%; large stock $58 \%$ ), but poor families invest all of their lactation efforts in small stock (95\%), with only $5 \%$ of total lactation output coming from large stock.

The 2009 drought also had significant effects on the overall herd compositions (lactating and non-lactating) among families of different social strata (Figure 19). Wealthy families experienced larger absolute reductions in goats and sheep than poorer families (goats: $U=11$, $-2.235, p<0.03$; sheep: $U=15,-2.445, p<0.01)$. Similarly, wealthy families faced greater absolute losses in cattle and camels than poor families (cattle: $U=11$, -2.922, $p<0.0035$; camels: $U=17,-3.437, p<0.0006)$. Poor and wealthy families fared equally well with their chicken populations $(U=37.5,-0.053, p<0.975)$; in fact, both groups increased their chicken numbers after the drought.

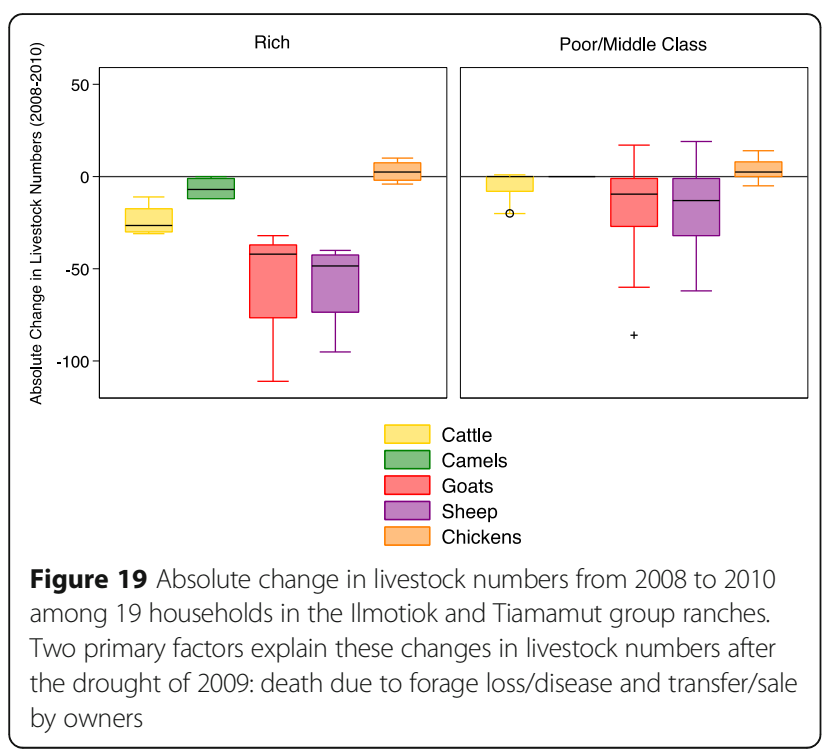

Data we collected on absolute numbers of livestock births, deaths, transactions, and exchanges indicates that three primary factors drive changes in herd size and species composition during and after drought (Figure 19). For wealthy families, having larger absolute herd sizes means greater numbers of births (absolute numbers of infants born: $U=1,586,6.016, p<0.00001$ ) and excess stock to slaughter for ceremonies and rituals (slaughters, all species: $U=33,2.790, p<0.0053)$. Wealthy families purchased stock to rebuild their herds when times were bad $(U=108.5,2.592, p<0.0095)$ suggesting that these households prioritize year round herd building via stock purchases.

Both poor/middle class families and rich families lost significant proportions of their herds to death, either from disease or starvation (deaths, total: $U=83.5$, $1.029, p<0.30)$. There were no significant differences between rich and poor/middle class in the numbers of livestock sold (sold, all species: $U=556.5,1.460, p<$ $0.64)$ or gifted $(U=34,0.667, p<0.50)$ (Figure 20$)$. When the results in figures 19 and 20 are converted to a common currency of TLUs as described in the Methods section, wealthy herders who enter the drought with higher TLUs (for rich, $M=80.56, \mathrm{SE}+/-8.72$; for poor, $M=18.57, \mathrm{SE}+/-5.41 ; t(16)=6.035, p<0.0001$, $N=17)$ then poor families, in fact do lose significantly more TLUs then poorer families (for rich, $M=54.17$, $\mathrm{SE}+/-7.33$; for poor $M=10.62$, $\mathrm{SE}+/-4.54 ; t(16)=$ $5.05, p<0.0001, N=17)$. But the wealthy do not lose relatively more then the poor (for rich, $M=0.68$, SE $+/-0.13$; for poor $M=0.41, \mathrm{SE}+/-0.08 ; t(16)=1.72$, $p<0.10, N=17)$. Consequently, when the drought ends they have significantly larger herds then the poor families (for rich, $M=26.38, \mathrm{SE}+/-4.20$; for poor $M=7.95$, $\mathrm{SE}+/-2.60 ; t(16)=3.729, p<0.0001, N=17)$. Therefore,

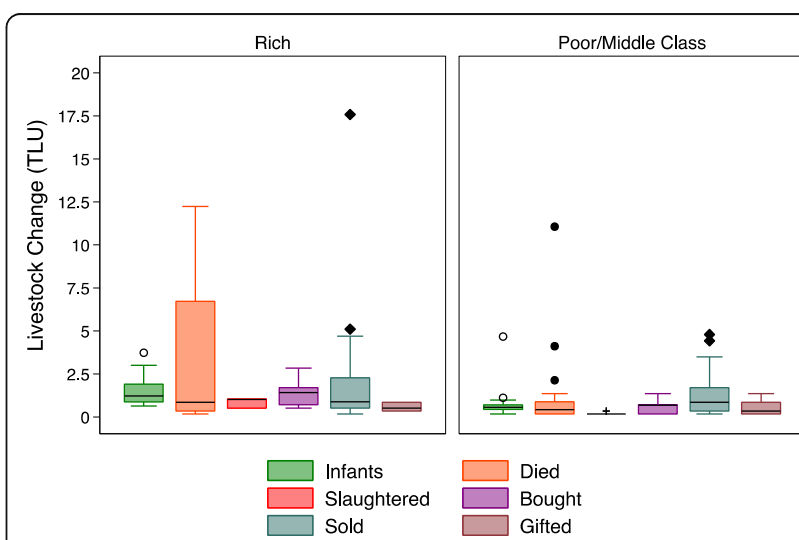

Figure $\mathbf{2 0}$ Factors facilitating changes in absolute number of livestock among different social strata. Significant differences exist between rich and poor/middle class families regarding changes to total livestock values under categories such as births, purchases, and slaughters 
because wealthy families have absolutely more TLUs then the poor, their herds can recover more rapidly then poor families after the drought ends.

\section{Discussion}

Our results demonstrate that there is a significant relationship between rainfall and vegetation potential in these communities and this relationship is directly tied to livestock productivity. During the last 10 years, rainfall events have been highly erratic in Mukugodo, making it difficult, if not impossible, for herders to predict when rain events will occur and generate adequate forage resources for their herds. Likewise, when we investigated rainfall patterns over the 60 -year period prior to our study, we found a similar pattern. Rainfall events have been highly variable over the last 60 years, with significant changes in rainfall levels after the 1980s. Conditions appear to be drying out over time; this is evident particularly in later part of the twentieth century, where rainfall levels start to show a downward trend. Analysis of the correlation between NDVI and rainfall at a lag of one month (the time it takes for vegetation to respond to rainfall) indicates that vegetation growth is directly tied to rainfall events. Hence, we can reject that null hypothesis that there is no significant relationship between rainfall events and vegetation growth. Similarly, we can reject the null hypothesis that livestock productivity is not tied to vegetation. There was a strong correlation between milk production (our measure of livestock productivity) and NDVI, indicating that livestock productivity, in the form of milk yields, directly responds to improvements in vegetation.

Under these conditions, the ability to migrate to grazing areas rich in water and forage resources is crucial if rainfall levels in the home patch are not frequent or heavy enough to cause vegetation growth or improvement. As such, we evaluated the options of our herders based on rainfall differences between home patches and a number of important regional migration patches in Laikipia. Based on rainfall differences alone, we predicted that herders should use a fixed set of patches depending on which group ranch they originated from. However, before and during the drought of 2009, herders do not behave according to rainfall and NDVI alone. This indicates that there may be other factors, such as what type of herd an individual owns (cattle, sheep, or goats or a mixture of the three), their ability to acquire free labour to migrate to a squatter parcel rather than using rented labour, and access to private parcels of land that my be unavailable to other herds, which reduces competition for resources with other herders on crowded grazing lands. This analysis also showed us that herders change their behavior after the drought (presumably in response to losses incurred during the drought due to poor migration decisions or lack thereof) in both communities. Both sets of herders seem to make more of their decisions based on rainfall and forage growth after the drought when regional parcels are less crowded and conditions less dire, making it easier for families to negotiate access or find the required labour to migrate.

Wealthy families have an advantage when it comes to access to grazing patches, both distant and local. For example, based on rainfall differences alone, no herder should move to Sukuton for grazing. However, given its close proximity to Mpala (which provides security patrols near the borders and nearby dams), many herders choose to move there, presumably because it is safer and closer to home than more distant patches that may have better quality grazing. Furthermore, herders whose herds are too large to be absorbed by Mpala, which can only accommodate a limited number of animals onto its land during any given season (100-150 animals per season from all group ranches), must be moved elsewhere. Typically the grazing patches bordering a rented patch (such as Sukuton/Endana) or patches bordering land on your own patch (Koija in the case of Tiamamut GR) have similar although not ideal conditions to the patches with higher overall rainfall (green up of grass, ease of access, less crowding). Making the "best of a bad situation" means that both poor/middle class families and rich families must make decisions that are not ideal in order to provide some sort of water or grazing support for their animals during hard times. Access to cash means that wealthy families can move their animals farther distances if they choose to do so. As we have seen in this paper, some wealthy families chose to use patches closer to home (Koija for wealthy Tiamamut herders, for example) because they have family relations or social affines in those patches that provide free support. Wealthy families that choose to move to distant patches have to hire herding labour or split their household, both choices that may not be convenient or expedient. Ultimately, wealthy herders, because of their social connectedness and access to cash can choose to move to any patch of land they want, giving them much greater flexibility than their poorer neighbors at home.

Secondly, wealthy families seem to be better at negotiating rights of access to high quality grazing patches outside of their home range, making it easier for them to reach these distant patches before they are used up. We suggest that dual access to private transportation and reliable, timely information via cell phone (both a result of greater access to cash) is the major difference between these two classes. Two of the wealthy families in our study owned private motorcycles and reported driving out to new grazing patches before sending affines or hired herders there to graze. Having their own 
transportation gives them an advantage over herders dependent on local information; timely access to better information about patch quality allows them to make more informed decisions about where to migrate or when. Access to transportation means they can also regularly visit their satellite stock camps and monitor the progress of the herd so as to make well-timed decisions about when to migrate, sell off improved stock, and breed existing stock, among others.

We should not exclude the option that herders without access to transportation can also use telephones to call affines and relatives living near these distant patches, thereby gaining up-to-the-minute information on patch quality. Families of all social strata own cell phones these days, making it easier for everyone to gain similar information about distant areas. In our study, wealthy families report exclusive access to patches close to optimal migration zones (for example, in the Aberdares Mountains near Rumuruti Approach). These exclusive arrangements may in part be facilitated by increased access to cash, labour, and/or transportation (read: globalization), which allows rich families to use superlative grazing patches to build up their herds. There are two problems with this choice, however. Moving herds to distant patches to be herded by affines or outsiders means that immediate family members back at home will not have access to the benefits of their increased production. This means that although their herds can recover more quickly (such as in increased birth and/or lactation rates) than their compatriots back in the home patch, they lose the subsistence benefit that the poor herders theoretically gain who do not move. Hence, as our conceptual model (Figure 1) demonstrates in the new boxes on markets and social assistance, families with greater access to markets- which will generate new and larger forms of cash than previously- and favorable terms of trade (grazing or market access) will be able to move their herds more effectively, purchase stock to rebuild their herds, and require less assistance from social welfare programmes, leading those families to be able to recover more effectively during difficult periods or droughts.

Wealth differences in grazing access exist at home as well. Herders in Tiamamut have greater access to watering places for their stock, meaning their overall travel time to water is shorter, leaving more time for grazing. Increased grazing time means healthier livestock, a higher market value, and more favourable terms of trade in the market when they go to sell. Herders in Ilmotiok travel longer distances to water, since their only major water point is the river on the western side of the ranch. Herders in Ilmotiok also travel longer herding radii to complete their grazing path, meaning the long treks to water reduce the amount of grazing they can access. Herders must stay out longer and move greater distances to achieve the same level of grazing. This limits poorer households, whose herd sizes are much smaller anyway, to reduced herd growth, lower market value, and decreased terms of trade in the market. This leads poor families to be dependent on social welfare programmes to feed their families, since neither milk production at home nor livestock sales alone can sustain these families. Poor families must access food aid programmes, supplemental feeding programmes, or other social programmes to maintain their families when internal social structures breakdown. While rich families can use cash and smart herd growth to improve their livelihoods after drought, poor families will continue to be dependent on external aid for survival.

Unfortunately, it seems that many of the internal social structures that worked to reduce income inequality among households in the past may also be breaking down. This was demonstrated during the recovery year in 2010, where we saw that income inequality among households increased. These increases (i.e. increased herd size or cash wealth) point to the ability of rich families to recover faster than poor and middle class households after critical events, such as drought. Similarly, lack of a significant difference between rich and poor households as with respect to gifts and exchanges revealed that gifting and exchange may no longer be a significant way for poorer individuals to replenish their milking herds after crisis or drought. In fact, over the entire study duration, we only recorded six livestock gifts, two of which were from a poor family to a rich family who had assisted them during the drought. Again, this suggests that rich households are no longer giving out large numbers of stock to disadvantaged herders as a means to redistribute wealth.

For example, rich families reported distributing cash to families asking for paran instead of livestock; this shift disadvantages poor herders who gain a temporary cash benefit but not a long-term subsistence benefit from a gift of a lactating animal, as they would have in the past. This may indicate a breakdown in traditional practices in this system (Aktipis et al. 2011; Cronk 1991; Cronk 2007; Herren 1987). This result is not surprising since stratification and inequality usually appear in areas where there are alternative forms of resource and labour acquisition, such as access to land rights, permanent wells or dams, and cash (Dahl and Hjort 1976). Similarly, we suggest that the breakdown of social welfare systems may be due to greater access to cash or other necessary herd or household inputs among some families but not others. For example, rich families could distribute cash to poor families instead of livestock or use cash to buy alternative protein sources thereby milking their own livestock less, allowing for greater investment in calf growth since calves consume the majority of production (Dahl and Hjort 1976). 
Our results on milk production indicate that milk yields of poor families did not improve in 2010 and 2011. We suggest this occurred because the majority of poor families divested themselves of large stock in exchange for 95\% investment in small stock. Milk yields from small stock are generally low, but provide the majority of milk for human consumption in many parts of Kenya (Dahl and Hjort 1976). Goats yield on average $88 \mathrm{ml} /$ day, but some breeds, such as the Nubian, can reach upwards of $500 \mathrm{ml} /$ day (Dahl and Hjort 1976). The upper limit on shoat lactation is 150 days, with most producing milk for 90 to 120 days. Offspring consume approximately $50 \%$ of the total production. Sheep are constrained to lactate only after the long rains in May, but goats can lactate at any time so they are an important source of milk in dry seasons. During normal lactation, goats can produce $690 \mathrm{ml} /$ day and sheep 520 $\mathrm{ml} /$ day, although only $50 \%$ of this is generally removed for human use. If breeding at two cycles per year, herders can expect about 100 to 120 days of milk production. Lactation levels generally range between 16\% and $60 \%$ in these herds, with maximum daily yields occurring 8 to 12 weeks after birth.

Shoats are good sellers in the market (Dahl and Hjort 1976). There is a high demand for goat meat from the few urban centres in Laikipia, making shoat production profitable (Zaal and Dietz 1999). However, small stock production is risky; they are more prone to disease and death than cattle or camels, especially sheep. Sheep need constant water and grass, making them very weak in drought and susceptible to disease. In particular, sheep are selective grazers that need grass that regenerates at regular intervals or else they drastically drop milk levels. On the other hand, goats can be watered every two to four days (Mike Littlewood, personal communication, 2011). Goats do not respond by dropping milk levels when drought or dry seasons occur because they can eat other vegetation (forbs, browse, tree cuttings, pods) making them more versatile and dependable (Nicholson 1984). Goats recover faster after drought; within five to six months of rain they can be producing milk again, which is essential for poor families with limited stock numbers (Hauck, personal observation).

Small stock cannot produce as much milk per animal, so poor families who invest in small stock are disadvantaged in subsistence production in contrast to wealthy families who can invest 50/50 in large and small stock, yielding better overall milk yields. Milk production declined for all families during the drought in 2009. During this period, herd sizes and milk yields decreased precipitously for all classes in both group ranches. Significant differences in household production outcomes fully emerged during the recovery in 2010, where rich and poor herders both reported improved yields. This points to the importance of local rainfall and vegetation for the maintenance of milk production at the household level.

Overall, herders in Mukugodo are using mobility as a strategy to improve livestock production during dry seasons and droughts. Some herders also move their animals to regional patches during good seasons, suggesting that they are seeking the highest quality patches to generate the fattest, healthiest stock for sale in the market rather than to generate high milk yields for home consumption. These herding differences separate families not only by group ranch, in that they behave differently based on where they live, but also by wealth class, where having access to resources external to the system provides herders with an advantage over their compatriots at home.

\section{Conclusion}

Semi-arid ecosystems around the world are drying out and global economic conditions are shifting due to climate change. Subsistence pastoralism, in isolation, no longer exists. It has declined as a practice because of increasingly erratic rainfall, dried out and dying grasslands, rapid population growth, and restrictions on household and herd mobility, such as sedenterisation or privatization of land.

We believe that the conceptual framework generated in this paper allows pastoral scholars to articulate some of the recent environmental and economic shifts leading pastoral families to move outside of the pastoral sector and tap into the global economy. In response to recent declines in semi-arid ecosystems noted above, pastoralists seek alternatives by working for private ranches or conservation organizations, working as hired herders or engaging in non-pastoral activities such as charcoal production, migrating to cities to engage in education or wage labour, and/or investing in local eco-tourism ventures. These diverse approaches are not mutually exclusive but complementary.

The emergence of globalized markets and the integration of globalized production in developing countries has forced many pastoralists, as well as the rest of the world's consumers, to shift their economic strategies of production to accommodate continuously evolving markets. Within the pastoral lexicon, scholars have oft proposed that to survive over the long term, pastoral livelihoods must remain static thus reasserting the incorrect notion that pastoralists should remain undeveloped, amid unjustifiable conditions of non-market transactions, unpaid labour, and non-capitalist enterprises. This perspective, although sensitive to the social and cultural desires of some pastoral populations, discounts the significant dynamics of production and exchange that are now dependent on and entrenched in our newly emerging global environment. 
Bottom up perspectives on pastoral economics use elements of a "survival economy" approach to distinguish between different pastoral livelihood strategies. Under an economy of survival, insecure (read: poor) individuals use risk spreading techniques to "survive" rather than trying to maximize profits to improve their livelihoods. Poor and vulnerable individuals suffer precipitous declines in household food consumption under global market engagement, particularly during periods when food prices rise and livestock prices decline, leading to increased levels of food insecurity and malnutrition. Risky livestock markets and unfavourable terms of trade may deter pastoral families from engaging in livestock transactions, reducing their ability to acquire cash to feed their families and save for the future.

Although we cannot deny that there may be long term benefits associated with global market opportunities, these benefits are not equitably distributed or experienced by pastoral populations. However, several different complementary economic practices may generate household revenues, and these revenues are often redistributed via remittances to the entire family network. Numerous individuals in a single family may be simultaneously engaged in diverse economic activities, all of which contribute a small amount to overall household needs. Effectively, pastoral households diversify revenue streams much in the same way that stockbrokers diversify portfolios of stocks and bonds in the market to spread their risk.

Pastoralists may also engage in a variety of other activities outside of the pastoral sector to spread risk. These activities include charcoal production, petty trade in beads, alcohol production, and other forms of home based trade. These revenues, although meager, may be the only form of cash for families devoid of livestock. Individuals who cannot work for wage labour or generate cash revenue may perform important social and familial functions, providing essential non-cash services to households. As such, individuals in a single household can be oriented towards both subsistence and market production simultaneously.

Ultimately, by fighting to maintain local resources under their immediate control, pastoralists seek reliability in an inherently unpredictable and competitive global world. It is the quantifiable outcomes of these different approaches to modern livelihood challenges that allow us to evaluate the impact of new economic opportunities on human health and well-being for pastoral families now and in the future.

\section{Endnotes}

${ }^{1}$ For more information on NDVI, please see www.usgs.gov
${ }^{2}$ For more information, please visit Kenya's International Livestock Research Institute www.ilri.org

${ }^{3}$ If wives were surveyed on livestock transactions when husbands were absent, they often did not know the value of the livestock sold by their husbands or were not told the value of the transaction. In these cases, we did not record a transaction value for that animal. However, we can use market prices to estimate the value of animals sold based on age, sex, and month of transaction.

${ }^{4}$ The World Health Organization Equity Assessment Tool is freely available on the Internet (www.who.org).

${ }^{5}$ The Gini coefficient is a measure of statistical dispersion developed in Italy in 1912. It measures the degree of inequality in a frequency distribution of values, such as income. Worldwide values of Gini coefficients range from highly equal (Slovenia; 0.24) to highly unequal (South Africa; 0.70). Higher values indicate greater inequality. For more information, please see World Bank PovCalnet http://iresearch.worldbank.org/PovcalNet/

${ }^{6}$ Theil's $T$ is a measure of economic inequality developed in the Netherlands by Henri Theil (successor of Tinbergen). It is a special case of the generalized entropy theory, similar to a Shannon index, where $T=$ maximum possible entropy of the data - observed entropy of the data. The index measures the entropic distance (how far away) the population exhibits away from an idealized egalitarian state where incomes are equal. A higher Theil's $\mathrm{T}$ index (ranging from 0 to $\infty$ ) means incomes are not evenly distributed among individuals. For a simple overview, please see Wikipedia (www.wikipedia.org)

${ }^{7}$ All rainfall data were taken from the Texas A\&M Global Livestock Early Warning System (GLEWS) database for Laikipia, Kenya, as previously explained in detail in the 'Methods' section.For complete datasets, please visit: http://glews.tamu.edu/eastafrica

\section{Acknowledgements}

Here I gratefully acknowledge the communities of Ilmotiok and Tiamamut who allowed me to enter their homes and learn about their lives as pastoralists in rural Kenya. The staff, researchers, and local community at Mpala Research Center were extremely helpful and supportive during the data collection portion of this study. I also acknowledge my colleagues and collaborators at Princeton for their support during the writing of this manuscript.

\section{Funding}

Princeton University's Department of Ecology and Evolutionary Biology and Princeton University's Grand Challenges Development Fund provided funding for this research. Our funding agencies did not play a role in the design of the study and/or collection, analysis, and interpretation of data and writing of the manuscript.

\section{Availability of data and materials}

The climatic data utilized in this paper is publically available at http:// glews.tamu.edu. The household datasets supporting the conclusions of this article are subject to IRB protections and are therefore not listed in any publically accessible database. For more information on how to receive a redacted version of data supporting this paper, please contact the lead author. 


\section{Authors' contributions}

SH designed the study, collected the data, analysed all data and generated climatic models, synthesized written materials, generated the model, and wrote the manuscript. DR assisted with model development, research methods, and editing of the manuscript. Both authors read and approved the final manuscript.

\section{Authors' information}

S.H. holds a Ph.D. in Ecology and Evolutionary Biology from Princeton University. She has spent the last 15 years conducting research and living side by side with pastoral communities in Tanzania, Kenya, and South Sudan. D.I.R. is the Class of 1877 Professor of Zoology in the Department of Ecology and Evolutionary Biology at Princeton University. He has been working in rural Kenya for over 35 years on wildlife conservation and human-wildlife conflict. He is the Director of African Studies at Princeton University.

\section{Competing interests}

The authors declare that they have no competing interests.

\section{Ethics Approval and consent to participate}

Ethical approval was granted under Institutional Review Board for the Ethical Treatment of Human Subjects at Princeton University (Protocol \# 4051).

\section{Publisher's Note}

Springer Nature remains neutral with regard to jurisdictional claims in published maps and institutional affiliations.

\section{Received: 6 November 2016 Accepted: 11 May 2017} Published online: 04 July 2017

\section{References}

Aktipis, C.A., L. Cronk, and R. Aguiar. 2011. Risk-pooling and herd survival: An agentbased model of a Maasai gift-giving system. Human Ecology 39: 131-140.

Bekure, S., P.N. de Leeuw, B.E. Grandin, and P.J.H. Neate (eds.). 1981. Maasai herding: An analysis of the livestock production system of Maasai pastoralists in eastern Kajiado District, Kenya. Nairobi: ILCA.

Bollig, M., and C. Lesorogol. 2016. The "new pastoral commons" of Eastern and Southern Africa. International Journal of the Commons. 10(2): 665-687.

Bond, J. 2014. Conflict, development, and security at the agro-pastoralwildlife nexus: A case of Laikipia County, Kenya. Journal of Development Studies 50(7): 991-1008.

Boone, R.B., and G. Wang. 2007. Cattle dynamics in African grazing systems under variable climates. Journal of Arid Environments 70: 495-513.

Borgerhoff Mulder, M. 1992. Demography of pastoralists: Preliminary data on the Datoga of Tanzania. Human Ecology 20: 383-405.

Brinkman H, Pee S De, Sanogo I, Subran L, Bloem MW. 2010. High food prices and the Global Financial Crisis have reduced access to nutritious food and worsened nutritional status and health. Journal of Nutrition 140 (1): 1535-1615, Supplement.

Butt, B. 2010. Seasonal space-time dynamics of cattle behavior and mobility among Maasai pastoralists in semi-arid Kenya. Journal of Arid Environments 74: 403-413.

Butt, B. 2011. Coping with uncertainty and variability: The influence of protected areas on pastoral herding strategies in East Africa. Human Ecology 39: 289-307.

Catley, A., J. Lind, and I. Scoones. 2013. Pastoralism and development in Africa: Dynamic change at the margins. New York: Routledge.

Christian, P. 2010. Impact of the economic crisis and increase in food prices on child mortality: Exploring nutritional pathways. Journal of Nutrition 140: 177S-181S.

Cleveland, W.S. 1979. Robust locally weighted regression and smoothing scatterplots. Journal of the American Statistical Association 74: 829-836.

Cronk, L. 1991. Wealth, status, and reproductive success among the Mukugodo of Kenya. American Anthropologist 93: 345-360.

Cronk, L. 2004. From Mukugodo to Maasai: Ethnicity and cultural change. Boulder: Westview Press.

Cronk, L. 2007. The influence of cultural framing on play in the trust game: A Maasai example. Evolution and Human Behavior 28: 352-358.

Dahl, G., and A. Hjort. 1976. Having herds: Pastoral herd growth and household economy. Stockholm: Dept of Social Anthropology, University of Stockholm.
Darmon, N., and E.L. Ferguson. 2002. A cost constraint alone has adverse effects on food selection and nutrient density: An analysis of human diets by linear programming. The Journal of Nutrition 132: 3764-3771.

Deaton, A. 1997. The analysis of household surveys: A microeconomic approach to development policy. Baltimore: John Hopkins University Press.

Dietz, T., A.A. Nunow, A.W. Roba, F. Zaal, M. Salih, A. Ghaffar, and M. Ahmed. 2001 Pastoral commercialisation: On caloric terms of trade and related, African Pastoralism, Conflict, Institutions, and Government, 194-234. London: Pluto Press.

Escudero, W.S., and L. Gasparini. 2000. A note on the statistical significance of changes in inequality. Economica La Plata 46: 111-122.

Fratkin, E., and E.A. Roth. 1990. Drought and economic differentiation among Ariaal pastoralists of Kenya. Human Ecology 18: 385-402.

Fratkin, E., and E.A. Roth (eds.). 2005. As pastoralists settle: Social, health, and economic consequences of pastoral sedenterization in Marsabit District, Kenya. New York: Kluwer Academic Publishers.

Fratkin, E., M.A. Nathan, and E.A. Roth. 2006. Is settling good for pastoralists? The effects of pastoral sedenterization on children's nutrition, growth, and health among Rendille and Ariaal of Marsabit District, Northern Kenya. Presentation for "Pastoralism and Poverty Reduction in East Africa: A Policy Research Conference". Nairobi: International Livestock Research Institute

Gadd, M.E. 2005. Conservation outside of parks: Attitudes of local people in Laikipia, Kenya. Environmental Conservation 32: 50-63.

Galaty, J.G. 2016. Reasserting the commons: Pastoral contestations of private and state lands in East Africa. International Journal of the Commons 10(9): 709-727.

Gertel, J., and R. LeHeron (eds.). 2011. Economic spaces of pastoral production and commodity systems: Markets and livelihoods. Burlington: Ashgate Publishing Company.

Godoy, R., V. Reyes-García, T. Huanca, W.R. Leonard, R.G. Olvera, J. Bauchet, Z. Ma, J. John, M. Miodowski, O.Z. Rios, V. Vadez, and C. Seyfreid. 2007. The role of community and individuals in the formation of social capital. Human Ecology 35: 709-721.

Goldstein, H. 1968. Longitudinal studies and the measurement of change. The Statistician 18: 93-117.

Grandin, B.E. 1988a. Wealth ranking in small holder communities: A field manual. London: IT Publications, LTD.

Grandin, B.E. 1988b. Wealth and pastoral dairy production: A case study from Maasailand. Human Ecology 16: 1-21.

Herren, U. 1987. "Droughts have different tails": Response to crises in Mukugodo Division, North Central Kenya, 1950s-1980s. Disasters 15: 93-107.

Herren, U. 1988. Pastoral peasants: Household strategies in Mukugodo Division Laikipia District. Working paper no. 458. Nairobi: University of Nairobi, Institute for Development Studies.

Herren, U. 1989. The impact of wealth on smallstock production and utilization in a pastoral system: Mukugodo Division, Laikipia District, Kenya. Working paper no. 467. Nairobi: University of Nairobi, Institute for Development Studies.

Homewood, K. 1995. Development, demarcation and ecological outcomes in Maasailand. Africa: Journal of the International Africa Institute 65: $331-350$.

Homewood, K. 2004. Policy, environment and development in African rangelands. Environmental Science \& Policy 7: 125-143.

Homewood, K., and J. Lewis. 1987. Impact of drought on pastoral livestock in Baringo, Kenya 1983-85. Journal of Applied Ecology 24: 615-631.

Hughes, L. 2005. Malice in Maasailand: The historical roots of current political struggles. African Affairs 104: 207-224.

Huho, J.M., J.K.W. Ngaira, and H.O. Ogindo. 2009. Climate change and pastoral economy in Kenya: A blinking future. Acta Geological Sinica 83: 1017-1023.

Huho, J.M., J.K.W. Ngaira, and H.O. Ogindo. 2011. Living with drought: The case of the Maasai pastoralists of northern Kenya. Educational Research 2: 779-789.

Huysentruyt, M., C.B. Barrett, and J.G. McPeak. 2009. Understanding declining mobility and inter-household transfers among East African pastoralists. Economica 76: 315-336.

International Livestock Center for Africa (1981). Introduction to the East African Range Livestock Study, International Livestock Center for Africa (ILCA)/ Republic of Kenya, Nairobi.

Jandreau, C., and F. Berkes. 2016. Continuity and change within the socialecological and political landscape of the Masai Mara, Kenya. Pastoralism 6: 1.

Kaye-Zweibel EW .2011. Development aid and community public goods provision: A study of pastoralist communities in Kenya. PhD Paper. Princeton: Princeton University 
Kibet, S., M. Nyangito, L. MacOpiyo, and D. Kenfack. 2016. Tracing innovation pathways in the management of natural and social capital on Laikipia Maasai group ranches, Kenya. Pastoralism 6: 16.

King E. 2008. The dynamics of Sansevieria intermedia in degraded Kenyan drylands: Regime shift or resilience mechanism? in Proceedings of the VIIIth International Rangelands Congress, Hohhot

McCabe, J.T. 1987. Drought and recovery: Livestock dynamics among the Ngisonyoka Turkana of Kenya. Human Ecology 15: 371-389.

McCabe, J.T., P.W. Leslie, and L. Deluca. 2010. Adopting cultivation to remain pastoralists: The diversification of Maasai livelihoods in Northern Tanzania. Human Ecology 38: 321-334.

McPeak, J. 2004. Contrasting income shocks with asset shocks: Livestock sales in northern Kenya. Oxford Economic Papers 56: 263-284.

McPeak, J. 2005. Individual and collective rationality in pastoral production: Evidence from Northern Kenya. Human Ecology 33: 171-197.

Muthiani, E., J. Njoka, P. Kinyua, and G. Gitau. 2011. Partnership challenges of community wildlife sanctuaries in Laikipia County, Kenya. Nairobi: Paper presented at the KASAL program conference held at KARI HQ.

Mwangi, M. 2016. Diverse drought spatio-temporal trends, diverse etic-emic perceptions and knowledge implications for adaptive capacity and resource management for indigenous Maasai pastoralism in the rangelands of Kenya. Climate 4(2): 22.

Ngugi, M.K., and R.T. Conant. 2008. Ecological and social characterization of key resource areas in Kenyan rangelands. Journal of Arid Environments 72: 820-835.

Nicholson, M.J.L. 1984. Pastoralism and milk production. In: Smith, A.J. International Conference on Milk Production in Developing Countries. University of Edinburgh

Nkedianye, D., J. de Leeuw, J.O. Ogutu, M.Y. Said, T.L. Saidimu, S.C. Kifugo, D.S Kaelo, and R.S. Reid. 2011. Mobility and livestock mortality in communally used pastoral areas: The impact of the 2005-2006 drought on livestock mortality in Maasailand. Pastoralism 1: 17.

Omosa, E.K. 2005. The impact of water conflicts on pastoral livelihoods: The case of Wajir District in Kenya. Winnipeg: Report for the International Institute of Sustainable Development.

Oxby, C. 1981. Group ranches in Africa. Overseas Development Institute, London 2: 45-56.

Popkin, B.M. 1994. The nutrition transition in low-income countries: An emerging crisis. Nutrition Reviews 52: 285-298.

Popkin, B.M. 2006. Global nutrition dynamics: The world is shifting rapidly toward a diet linked with noncommunicable diseases. The American Journal of Clinical Nutrition 84: 289-98.

Ryan Z. 2004. Establishment and evaluation of a livestock early warning system for Laikipia, Kenya. Masters Thesis. Texas: Texas A\&M University

Scoones, I. 1995. Exploiting heterogeneity: Habitat use by cattle in dryland Zimbabwe. Journal of Arid Environments 29: 221-237.

Sellen, D.W. 1999. Polygyny and child growth in a traditional pastoral society: The case of the Datoga of Tanzania. Human Nature 10: 329-371.

Sellen, D.W. 2000. Seasonal ecology and nutritional status of women and children in a Tanzanian pastoral community. American Journal of Human Biology 12: 758-781.

Sellen, D.W. 2003. Nutritional consequences of wealth differentials in East African pastoralists: The case of the Datoga of Northern Tanzania. Human Ecology 31: 529-570.

Smith, E.A. 2011. Endless forms: Human behavioural diversity and evolved universals. Philosophical transactions of the Royal Society of London. Series B, Biological sciences 366: 325-32.

Spear, T., and R. Waller (eds.). 1993. Being Maasai. Dar es Salaam: Mkuki na Nyota.

Spencer, P. 1959. The relocation of the Leuaso Dorobo of Kenya: Report prepared at the request of Charles Chenevix Trench. Samburu District: District Commissioner.

Taylor, D., P.J. Lane, V. Muiruri, A. Ruttledge, R.G. McKeever, T. Nolan, P. Kenny, and R. Goodhue. 2005. Mid- to late-Holocene vegetation dynamics on the Laikipia Plateau, Kenya. The Holocene 15: 837-846.

Thornton, P.K., R.B. Boone, K.A. Galvin, S.B. BurnSilver, M.M. Waithaka, J. Kuyiah, S. Karanja, E. González-Estrada, and M. Herrero. 2007. Coping strategies in livestock-dependent households in East and Southern Africa: A synthesis of four case studies. Human Ecology 35: 461-476.

Verbyla, D. 1995. Satellite remote sensing of natural resources. New York: CRC Press.

Wambuguh, O. 2007. Interactions between humans and wildlife: Landowner experiences regarding wildlife damage, ownership and benefits in Laikipia District, Kenya. Conservation and Society 5: 408-428.
Watson, E.E., H.H. Kochore, and B.H. Dabasso. 2016. Camels and climate resistance: Adaptation in Northern Kenya. Human Ecology 44: 701.

Yanda, P.Z., and C. William. 2010. Livelihoods diversifications and implications on food security and poverty levels in the Maasai plains: The case of Simanjiro district, Northern Tanzania. African Journal of Environmental Science And Technology 4: 154-166.

Zaal, F. 1999. Pastoralism in a global age: Livestock marketing and pastoral commercial activities in Kenya and Burkina Faso. Amsterdam: Thela Thesis.

Zaal, F., and A.J. Dietz. 1999. Of markets, meat, maize and milk: Pastoral commoditization in Kenya. In The poor are not use us: Poverty and pastoralism in Eastern Africa, ed. D. Anderson and V. Broch-Due, 163-198. London: James Currey Ltd.

\section{Submit your manuscript to a SpringerOpen ${ }^{\mathcal{O}}$ journal and benefit from:}

- Convenient online submission

- Rigorous peer review

- Open access: articles freely available online

- High visibility within the field

- Retaining the copyright to your article

Submit your next manuscript at springeropen.com 